\title{
THE
}

\section{Westward-propagating SST Anomalies and Baroclinic Eddies in the Sargasso Sea}

George R. Halliwell Jr.

Young Jae Ro

Peter C. Cornillon

University of Rhode Island, pcornillon@uri.edu

\section{Citation/Publisher Attribution}

Halliwell, G.R., Y.J. Ro, and P. Cornillon, 1991: Westward-propagating SST Anomalies and Baroclinic Eddies in the Sargasso Sea. J. Phys. Oceanogr., 21, 1664-1680, https://doi.org/10.1175/ 1520-0485(1991)0212.0.CO;2

Available at: https://doi.org/10.1175/1520-0485(1991)021<1664:WPSAAB>2.0.C0;2

This Article is brought to you for free and open access by the Graduate School of Oceanography at DigitalCommons@URI. It has been accepted for inclusion in Graduate School of Oceanography Faculty Publications by an authorized administrator of DigitalCommons@URI. For more information, please contact digitalcommons-group@uri.edu. 


\title{
Westward-propagating SST Anomalies and Baroclinic Eddies in the Sargasso Sea ${ }^{\circledR}$
}

\author{
GeORge R. HALliwell, JR., ${ }^{*}$ YOUNG JAe Ro, ${ }^{* *}$ AND Peter CoRnillon ${ }^{\ddagger}$ \\ * MPO/RSMAS, University of Miami, Miami, Florida, \\ * Department of Oceanography, College of Natural Sciences, \\ Chung Nam National University, Kung-dong, Dae Jeon, Korea, \\ FGraduate School of Oceanography. University of Rhode Island, Narragansett, Rhode Island
}

(Manuscript received 23 July 1990, in final form 10 January 1991)

\begin{abstract}
Previous studies have documented the existence of a zonal band of strong, persistent, westward-propagating sea surface temperature $\left(T_{s}\right)$ anomalies with zonal wavelengths of $\approx 800 \mathrm{~km}$ and periods of $\approx 200$ days that are confined to the subtropical convergence zone (STCZ, roughly $26^{\circ}-32^{\circ} \mathrm{N}$ ). Two years of satellite-derived sea surface temperature $\left(T_{s}\right)$ and sea surface elevation anomaly $(\eta)$ maps of the Sargasso Sea $\left(22.5^{\circ}-33.5^{\circ} \mathrm{N}, 71.5^{\circ}-\right.$ $59.5^{\circ} \mathrm{W}$ ) are analyzed to determine how these anomalies are forced and why they are confined to the STCZ. A simple anomaly model forced by horizontal eddy currents and damped by a linear feedback mechanism explains many properties of the anomaly response. At wavelengths exceeding several hundred kilometers, forcing by horizontal eddy currents becomes less important relative to atmospheric forcing with increasing wavelength. The anomalies are confined to the STCZ partly because the large mean $T$, gradient there enables the horizontal eddy currents to be relatively effective at forcing anomalies. Also, the eddies that force these anomalies, wavelike features with wavelengths of $\sim 800 \mathrm{~km}$ and periods of $\sim 200$ days, are themselves confined to the STCZ. These wavelike eddies were not detected during earlier experiments such as MODE because the domains within which they were conducted were too small. Within the STCZ, zonal dispersion properties of the eddy field are consistent with baroclinic Rossby wave variability. To the north and south of the STCZ, however, zonal dispersion properties differ substantially from the properties observed within the STCZ. The eddy dispersion properties change abruptly across transition zones $1-2$ degrees wide centered at $32.5^{\circ}$ and $25.5^{\circ} \mathrm{N}$. A simple linearized reduced-gravity model is used to demonstrate that interaction between eddies and zonal mean currents can qualitatively account for the change is dispersion properties south of the STCZ, but not to the north within the Gulf Stream recirculation region.
\end{abstract}

\section{Introduction}

By analyzing a seven-year set of five-day composite sea surface temperature $\left(T_{s}\right)$ maps filtered to resolve wavelengths $\geqslant 220 \mathrm{~km}$ and periods $\geqslant 50$ days, Halliwell et al. (1990a) documented the properties of westwardpropagating $T_{s}$ anomaly features confined to the Sargasso Sea subtropical convergence zone (STCZ, roughly $26^{\circ}-32^{\circ} \mathrm{N}$ ) from 1982 to 1988 . Between $71^{\circ}$ and $59.5^{\circ} \mathrm{W}$, these features occasionally exceeded $\pm 1{ }^{\circ} \mathrm{C}$ in magnitude, had zonal wavelengths of $\sim 800 \mathrm{~km}$, periods of $\sim 200$ days, and propagated westward at 3$4 \mathrm{~km} \mathrm{day}^{-1}$. They were evident from fall to spring, with their magnitude, structure, and temporal persistence varying substantially from year to year. Individual

- FASINEX Contribution Number 105.

Corresponding author address: Dr. George R. Halliwell, Rosenstiel School of Marine and Atmospheric Science, Division of Meteorology and Physical Oceanography, 4600 Rickenbacker Causeway, Miami, FL 33149-1098. anomaly features could often be followed for several months. Their influence on measurements made during the Frontal Air-Sea Interaction Experiment (FASINEX; Weller 1991) is summarized in Halliwell and Cornillon (1990) and Halliwell et al. (1991b). Evidence suggested that the anomalies were driven by the baroclinic eddy field (Halliwell and Cornillon 1990; Halliwell 1991; Halliwell et al. 1991a).

Geosat altimetry data were obtained to determine how these anomaly features are forced by the baroclinic eddy field. We first describe the generation of the fiveday sea surface elevation anomaly $(\eta)$ maps. We show that the westward-propagating $T_{s}$ anomalies in the STCZ are strongly coupled to baroclinic eddies. We then use a simple model of $T_{s}$ anomaly variability to demonstrate that forcing by horizontal eddy currents dominates atmospheric forcing. Reasons why the westward-propagating $T_{s}$ anomalies are confined to the STCZ are identified. Eddy properties change dramatically with latitude, and the possible role of eddy-mean current interaction in producing this meridional variability is evaluated. 


\section{Creation of the $\eta$ maps}

Maps of $\eta$ were created for the same five-day intervals used for the $T_{s}$ maps (Halliwell et al. 1991a). The time interval for the present study is 19 November 1986 (the beginning of the Geosat Exact-Repeat Mission) to 14 October 1988, with both dates representing the central day of a five-day interval. Basic processing of the Geosat altimeter passes is described in Ro and Cornillon (1991); the resulting dataset consists of sea surface elevation anomaly along 42 sets of ascending tracks only, with each complete set spanning a period of about 17 days. These data were smoothed to reduce noise using a Hanning window about $75 \mathrm{~km}$ wide, then subsampled to a resolution of about $40 \mathrm{~km}$. Objective analysis (Carter and Robinson 1987) was then used to grid elevation anomaly maps on the same grid used for the $T_{s}$ maps (Halliwell et al. 1991a), except that the western edge was set at $71.5^{\circ} \mathrm{W}$ instead of $75.5^{\circ} \mathrm{W}$ because insufficient Geosat data were available farther west. The resulting grid has a resolution of $0.5^{\circ}$ latitude and longitude and spans the region from $22.5^{\circ}$ to $33.5^{\circ} \mathrm{N}$ and $71.5^{\circ}$ to $59.5^{\circ} \mathrm{W}$ (Fig. 1).

For the purpose of generating the $\eta$ maps, it was assumed that all data within each 17-day repeat cycle were sampled at the same time, namely, the middle of the time interval. This did not significantly degrade the analysis results presented here due to the low frequencies of the variability being investigated. The irregularly distributed input data in each 17-day interval were first spatially averaged within $0.5^{\circ}$ latitude/longitude boxes, then the resulting 42 gridded fields were used to estimate the three-dimensional autocorrelation function

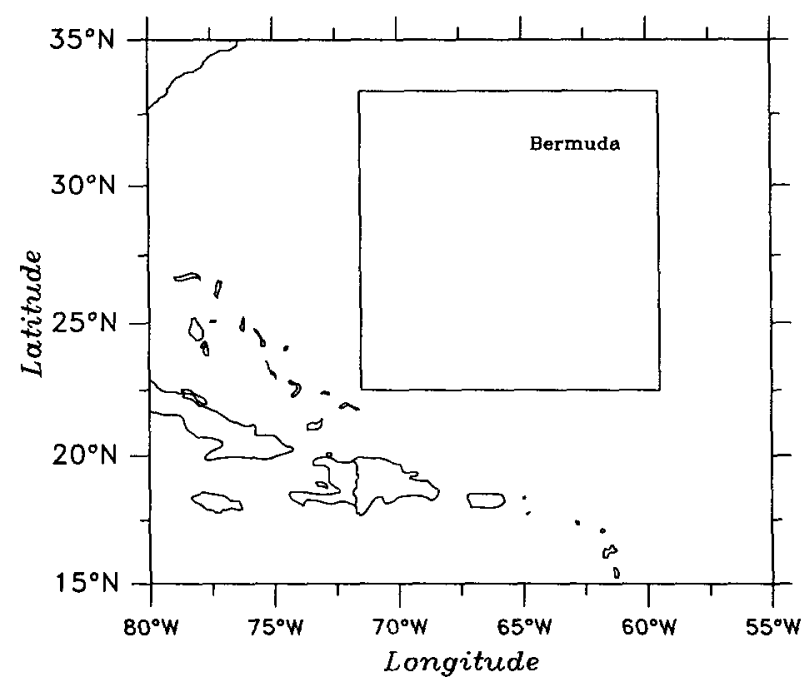

Analysis Domain

FiG. 1. The analysis domain (solid box), bounded by $22.5^{\circ}$ and $33.5^{\circ} \mathrm{N}, 71.5^{\circ}$ and $59.5^{\circ} \mathrm{W}$.

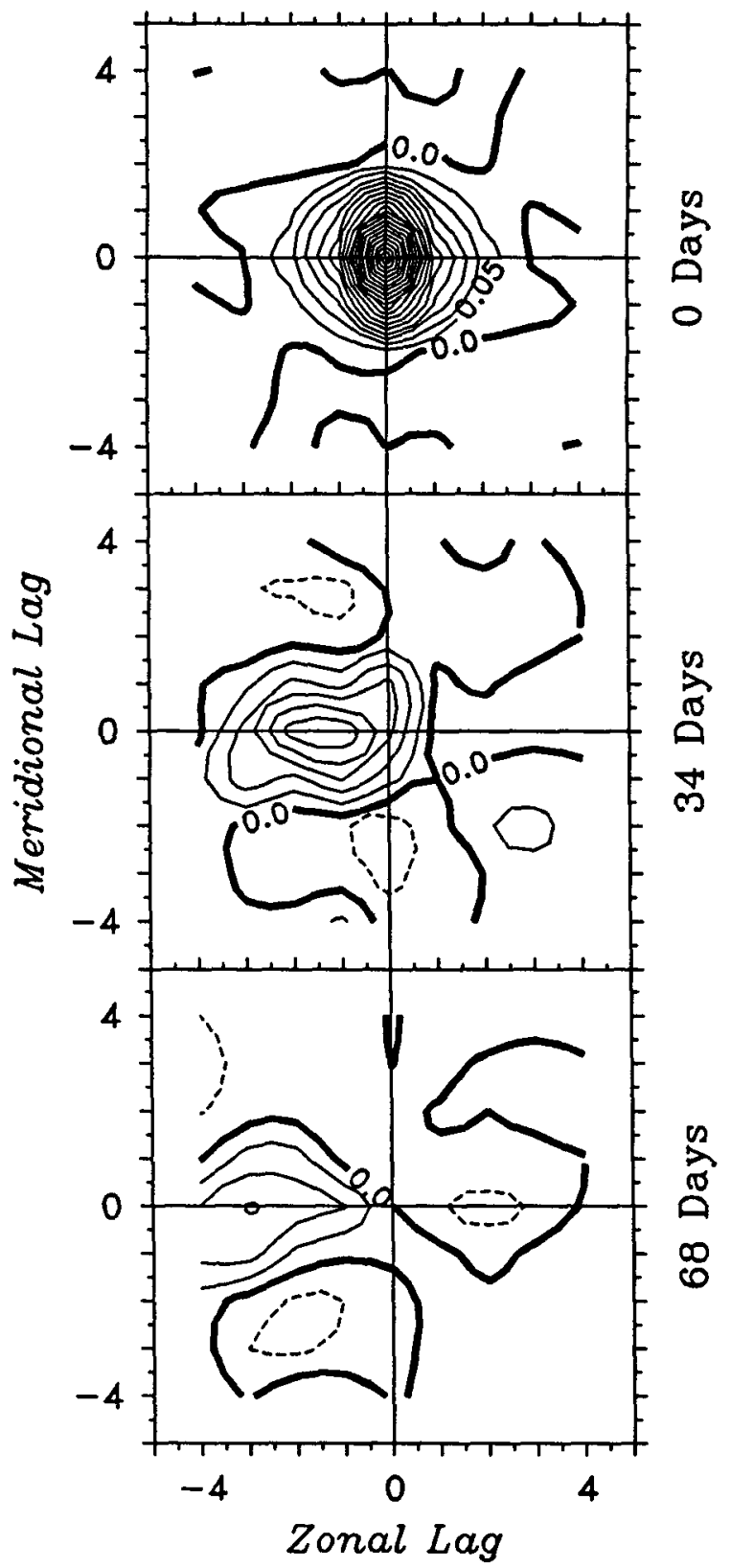

Fig. 2. Three-dimensional autocorrelation function estimated for the objective analysis of sea surface elevation. The function is graphed as a function of zonal and meridional lag distance in degrees longitude and latitude for three lag times: 0,34 , and 68 days. The contour interval is 0.05 . In this and other contour plots, dashed contours indicate negative values.

(Fig. 2) required for the objective analysis. The spatial resolution of this estimated correlation function was reduced to $0.05^{\circ}$ using bicubic spline interpolation, then it was stored as a lookup table for the correlation values required for the objective analysis based on zonal, meridional, and temporal lags. To interpolate 
elevation anomaly to a given grid point at a given time, a search was first conducted for all input data within $\pm 0.5^{\circ}( \pm 50 \mathrm{~km})$ in both $x$ and $y$, and within \pm 1 set of tracks ( \pm 17 days) in time. If fewer than eight data points were found, the box was then alternately expanded by $\pm 0.5^{\circ}$ in both space dimensions and by \pm 17 days in time until at least eight points were found. The number of box expansions was limited because input data values eventually become insignificantly correlated with variability at the interpolation point as the space/time separation increases. More than one input data value was always found by this search procedure. When more than eight data values were found, they were ranked according to the correlation index described in Halliwell et al. (1991a) and the eight "best" selected.

The same two-dimensional Shapiro filter (Shapiro 1970 ) used to spatially smooth the $T_{s}$ maps (Halliwell et al. 1991a), which produced a gain of 0.5 at a wavelength of about $220 \mathrm{~km}$, was used to smooth the elevation anomaly maps. A temporal cubic-spline interpolation was then performed at each grid point to generate the five-day maps of elevation. The same temporal Shapiro filter used for $T_{s}$, which produced a gain of 0.5 at a period of about 50 days, was used to low pass the five-day time series of elevation at each grid point. The resulting dataset consists of 140 five-day elevation maps. A small residual mean existed in the data processed by Ro and Cornillon (1991); it was removed to create the set of $\eta$ maps for analysis. To remove the variability of $\eta$ with wavelengths too large to be statistically resolved, a two-dimensional linear trend was removed from each $\eta$ map to generate a set of $\eta^{\prime}$ maps. Analogously, $T_{s}$ anomaly $\left(T_{s a}\right)$ maps were calculated by removing the mean seven-year annual cycle of $T_{s}$, then $T_{s a}^{\prime}$ maps were calculated by removing two-dimensional linear trends (Halliwell et al. 1991a).

Because of the relatively small spatial correlation scales, especially in the east-west direction (Fig. 2), along with the absence of descending tracks that could have provided data between the ascending tracks, errors in the objective analysis reached the same order of magnitude as the rms amplitude of the elevation field at some grid points located midway between tracks. Fortunately, the spatial filtering of the elevation maps smoothed the error field so that errors at all grid points in the $\eta$ maps were sufficiently small to allow the detection of eddies forcing the $T_{s}$ anomalies. Other sources of error did not seriously degrade the $\eta$ maps. Bisagni (1989) has analyzed atmospheric corrections to the Geosat altimeter, especially the water vapor correction, and has concluded that eddies with the wavelengths and periods of the $T_{s}$ anomaly features can be resolved with reasonably good accuracy. Also, since variability with periods $<50$ days has been filtered out, the influence of water vapor structure associated with synoptic atmospheric systems on $\eta$ has been largely averaged out (Jourdan et al. 1990).

\section{Coupling between eddies and anomalies in the STCZ}

The coupling is illustrated using zonal-time correlation analysis. If a zonal-time data matrix is dominated by a periodic propagating signal, then the zonaltime autocorrelation function will oscillate along the zonal and temporal lag axes with the zonal wavelength and period of the signal, respectively. The phase velocity of this signal can be estimated from the slope of the ridges and troughs of this function.

The $T_{s a}^{\prime}$ field is coupled to the $\eta^{\prime}$ field within the STCZ, and the strongest coupling is observed at $28.5^{\circ} \mathrm{N}$. At this latitude, the nearly identical structure of the zonal-time autocorrelation functions of both fields (Fig. 3 ) suggests that they are dominated by fluctuations with the same wavelength $(\sim 800 \mathrm{~km})$, period ( $\sim 200$ days), and zonal propagation velocity $(3-4 \mathrm{~km}$ day $^{-1}$ ). The cross-correlation function between the fields has the same structure as the two autocorrelation functions, but is phase shifted such that $T_{s a}^{\prime}$ leads $\eta^{\prime}$ both temporally by about one month and zonally by about $100 \mathrm{~km}$. This phase shift is qualitatively consistent with forcing by horizontal eddy currents since northward geostrophic current (warm heat advection) exists to the west of $\eta^{\prime}$ maxima. The maximum positive cross-correlation coefficient is 0.49 which, since it was calculated over ten zonal and six temporal correlation scales, is statistically significant at the $95 \%$ confidence level. The corresponding correlation functions calculated at $22.5^{\circ}$ and $33.5^{\circ} \mathrm{N}$ show that coupling is very weak north and south of the STCZ (Fig. 3). Also, the characteristic westward propagation speeds in the $\eta^{\prime}$ field are about twice as large outside of the STCZ. To examine the seasonal cycle of this coupling, zonal-time cross-correlation functions at $28.5^{\circ} \mathrm{N}$ between $\eta^{\prime}$ and $T_{s a}^{\prime}$ are calculated for winter $1986 / 87$ and summer 1987 (Fig. 4). Strong coupling exists during winter, with a maximum positive cross-correlation of 0.70 . Coupling is weak during summer since the maximum cross correlation is much smaller and the sloping ridgetrough pattern suggestive of westward phase propagation is gone. Westward propagation is present in the $\eta^{\prime}$ field, but not in the $T_{s a}^{\prime}$ field, during summer (not shown ).

To determine if the interannual variability in $T_{s}$ anomaly structure (Halliwell et al. 1991a) is related to interannual variability in the structure of the underlying eddies, zonal-meridional autocorrelation functions at zero lag time were calculated for $\eta^{\prime}$ and $T_{s a}^{\prime}$ between $26^{\circ}$ and $32^{\circ} \mathrm{N}$ (Fig. 5). The anomaly features were nearly isotropic during $1986 / 87$, and they were anisotropic during $1987 / 88$ with the major axis oriented southwest-northeast. The characteristic structures of the $T_{s a}^{\prime}$ and $\eta^{\prime}$ fields are very similar during both years, so the interannual variability in $T_{s}$ anomaly structure primarily reflects interannual variability in the structure of the associated baroclinic eddies. 


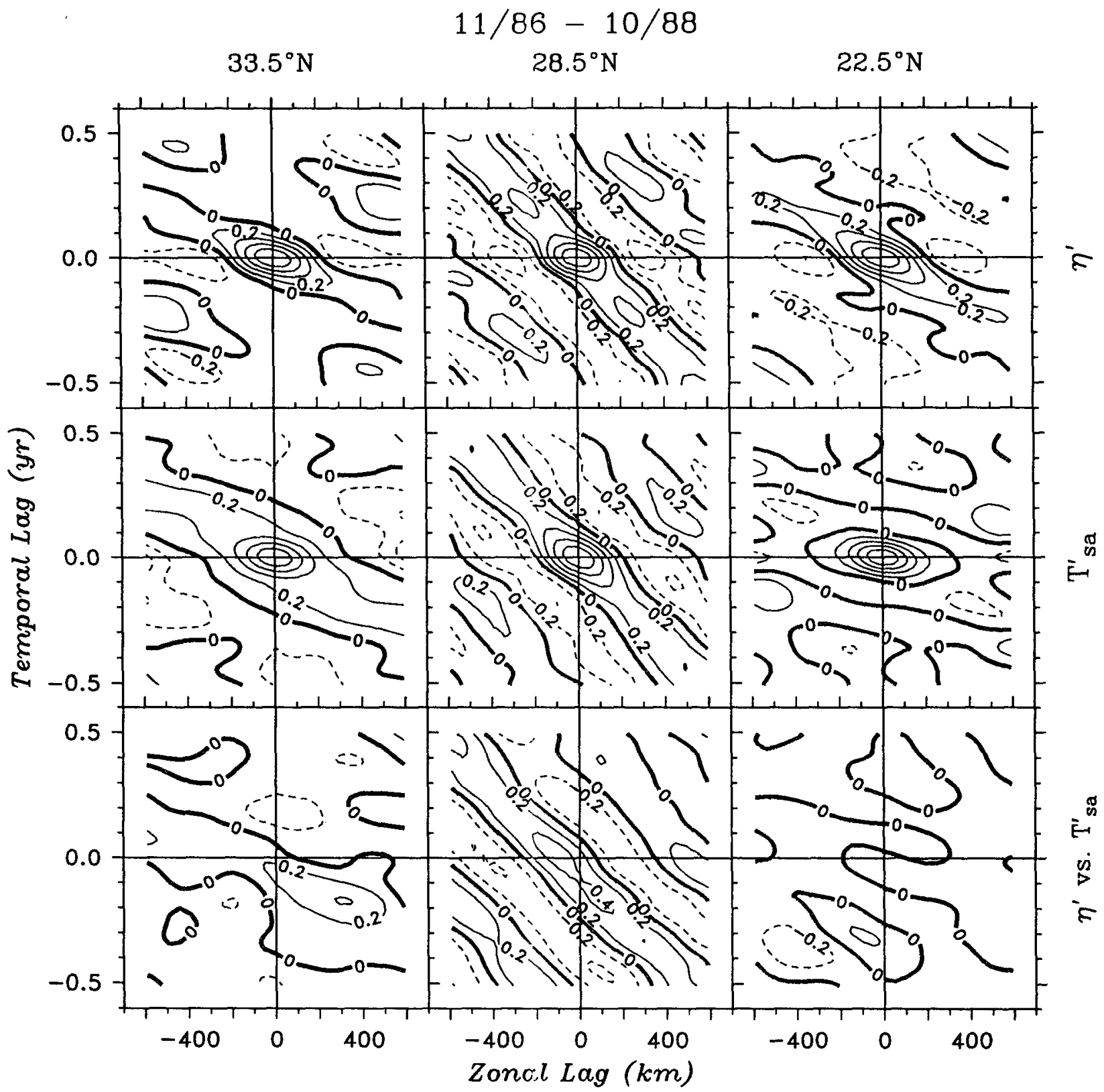

FIG. 3. Zonal-time autocorrelation functions of $\eta^{\prime}$ (top), $T_{s a}^{\prime}$ (middle), and cross-correlation functions between $\eta^{\prime}$ and $T_{s a}^{\prime}$ (bottom), at $33.5^{\circ} \mathrm{N}$ (left), $28.5^{\circ} \mathrm{N}$ (center), and $22.5^{\circ} \mathrm{N}$ (bottom), calculated over the 2-year interval.

Since earlier eddy experiments in the Sargasso Sea STCZ, such as MODE (MODE Group 1978), the POLYMODE Synoptic Experiment (PSE) (Harrison and Heinmiller 1983), and the POLYMODE Local Dynamics Experiment (PLDE) (Taft et al. 1986), were conducted within substantially smaller domains, the coupled eddies and anomalies resolved here were poorly resolved in these earlier experiments. For example, in geostrophic streamfunction maps calculated from MODE data within a 465-km square box centered near $28^{\circ} \mathrm{N}, 70^{\circ} \mathrm{W}$, peak-to-peak (and trough-totrough ) separation distances typically ranged between 250 and $400 \mathrm{~km}$ (McWilliams 1976). Similar separation distances dominated in PLDE dynamic height maps within a $250-\mathrm{km}$ square box centered about $3^{\circ}$ to the north of MODE (Shen et al. 1986), where in this case peak-to-peak separation was estimated as twice the distance between adjacent highs and lows due to the small domain size. The spatial lag of the first zero crossing in correlation functions calculated from 


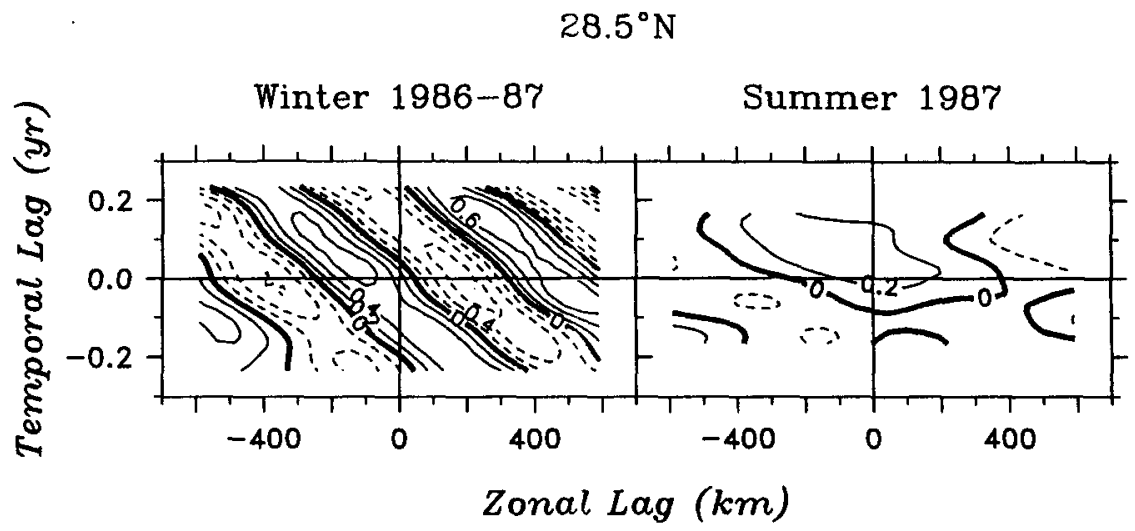

FIG. 4. Zonal-time cross-correlation functions between $\eta^{\prime}$ and $T_{s a}^{\prime}$ at $28.5^{\circ} \mathrm{N}$ for winter $1986 /$ 87 (mid-November 1986 through mid-May 1987) and summer 1987 (June through September).

MODE and PLDE data was typically about $120 \mathrm{~km}$ (e.g., McWilliams and Owens 1976; Carter and Robinson 1987), while it is about $200 \mathrm{~km}$ for both the $T_{s a}^{\prime}$ and $\eta^{\prime}$ fields in the present study. Eddy variability resolved in these earlier experiments was therefore dominated by wavelengths about half as long as those of the coupled eddies and anomalies described here. Some hint that larger-wavelength variability was present in the Sargasso Sea STCZ was obtained by Harrison and Heinmiller (1983) in upper-ocean temperature maps from the PSE due to the larger domain (about $600 \mathrm{~km} \mathrm{E}-\mathrm{W}$ by $900 \mathrm{~km} \mathrm{N-S}$ ), although this variability was still rather poorly resolved. Analyses of eddy field properties presented here thus extend results obtained in these earlier experiments to larger wavelengths and allow an assessment of how eddy properties vary as a function of wavelength to be made (section 6).

\section{Anomaly forcing in the STCZ \\ a. Anomaly heat balance model}

To analyze anomaly forcing, variables in the heat balance equation for a slab mixed layer are decomposed into a "mean" component (denoted by an overbar) and an anomaly component (denoted by subscript $a$ ) following Frankignoul (1985). The resulting anomaly heat balance is

$$
\frac{\partial T_{s a}}{\partial t}=F,
$$

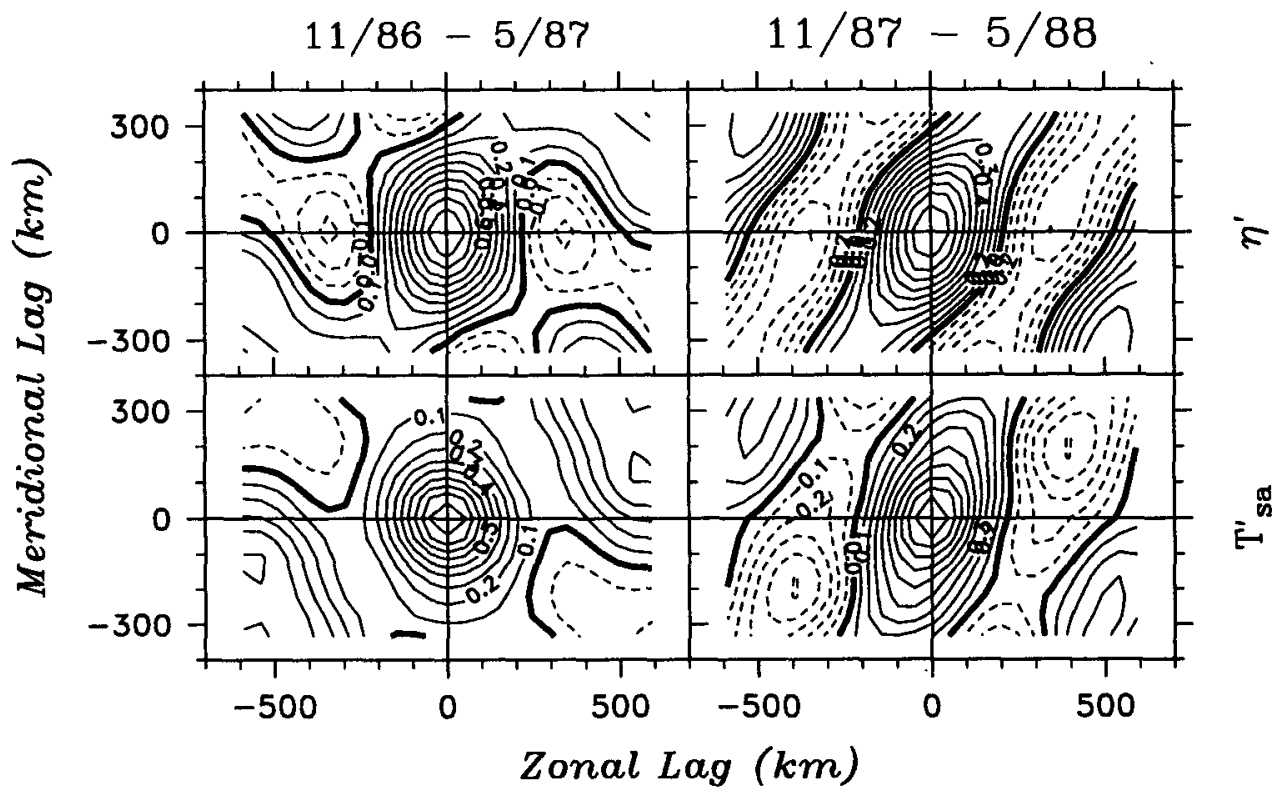

Fig. 5. Zonal-meridional autocorrelation functions at zero lag time of $\eta^{\prime}$ (top) and $T_{s a}^{\prime}$ (bottom) for the two winter ( $m i d-N o v e m b e r$ through mid-May) seasons. 
where

$$
\begin{aligned}
\left(\bar{h}+h_{a}\right) F= & -\frac{Q_{a}}{\rho c}-\left(h \mathbf{v}_{g}\right)_{a} \cdot \nabla\left(\bar{T}_{s}+T_{s a}\right) \\
& -\frac{\left(\vec{\tau}_{a} \times \mathbf{k}\right)}{\rho f} \cdot \nabla\left(\bar{T}_{s}+T_{s a}\right) \\
& -h_{a} \frac{\partial \bar{T}_{s}}{\partial t}-\Lambda\left(\bar{w}_{e}+w_{e a}\right)\left(T_{s a}-T_{+a}\right) \\
& -\Lambda w_{e a}\left(\bar{T}_{s}-\bar{T}_{+}\right),
\end{aligned}
$$

and where $h$ represènts mixed-layer depth, $Q$ net surface heat flux, $\rho$ water density, $c$ specific heat at constant pressure, $\mathbf{v}_{g}$ horizontal geostrophic current, $\vec{\tau}$ wind stress, $f$ Coriolis parameter, $\mathbf{k}$ vertical normal vector, $w_{e}$ vertical entrainment velocity at the mixed-layer base given by

$$
w_{e}=\frac{\partial h}{\partial t}+\nabla \cdot(h \mathbf{v})
$$

and subscript $+a$ depth just beneath the mixed-layer base. The parameter $\Lambda$ in (2) is 0 for $w_{e}<0$ and 1 otherwise since detrainment does not affect $T_{s}$. It has been assumed that $T_{s}$ equals the bulk mixed-layer temperature. The effects of mean current and horizontal diffusion have been neglected. Term 1 on the right side of (2) represents the influence of net surface vertical heat flux, term 2 horizontal eddy currents, term $3 \mathrm{Ek}$ man transport, term 4 a modification of $\partial T_{s a} / \partial t$ due to changes of $\bar{T}_{s}$ in the presence of anomalous mixedlayer thickness, and terms 5 and 6 net vertical heat flux at the mixed-layer base.

Two time scales of anomaly variability must be considered in (1) and (2): the low-frequency variability of the anomalies and eddies resolved here, and the higher-frequency (2-day to 2-week period) synoptic atmospheric variability. The eddies can directly force low-frequency anomalies by producing low-frequency variability of $h_{a},\left(h v_{g}\right)_{a}, w_{e a}$, and $T_{+a}$ in (2). Since the present dataset can only be used to estimate $\left(h v_{g}\right)_{a}$, we consider only the forcing by horizontal eddy currents in the present study. The atmospheric contribution to the forcing function $F$ in (2) through its influence on $Q_{a}, \vec{\tau}_{a}, h_{a}$, and $w_{e a}$ is also dominated by synoptic-scale variability. The atmospheric contribution to $F$ can therefore be considered a stochastic random variable at the low frequencies of the anomalies. Hasselmann (1976) has shown that in undamped linear models, stochastic forcing produces a low-frequency response that always increases in amplitude with time. Synoptic atmospheric forcing is assumed to generate low-frequency $T_{s}$ anomalies by this process (e.g., Frankignoul and Hasselmann 1977). The weaker low-frequency variability in atmospheric forcing is assumed to dampen the forced anomaly variability, primarily through the net vertical heat flux term in (2), by tend- ing to return the mixed layer to an equilibrium temperature that would exist in the absence of forcing (Frankignoul 1985).

If we assume that forcing by horizontal eddy currents can be simplified using

$$
\frac{\left(h \mathbf{v}_{g}\right)_{a}}{\left(\bar{h}+h_{a}\right)} \cdot \nabla\left(\bar{T}_{s}+T_{s a}\right) \approx v_{g} \bar{T}_{s y}
$$

then $F$ can be decomposed into stochastic atmospheric forcing $\left(F_{A}\right)$, eddy forcing (due to horizontal heat advection only), and linear feedback components as follows:

$$
F=F_{A}-v_{g} \bar{T}_{s y}-\lambda T_{s a},
$$

where $\lambda$ is the damping coefficient.

\section{b. Atmospheric forcing of anomalies in the STCZ}

Neglecting the eddy-forcing term, the model (1) and (5) can successfully predict many properties of largescale, low-frequency $T_{s}$ anomalies in open-ocean regions where the influence of eddies and mean currents on the mixed-layer heat balance are relatively unimportant (e.g., Frankignoul and Hasselmann 1977; Reynolds 1979; Frankignoul and Reynolds 1983). However, when such tests are conducted in regions where eddy forcing is important, anomaly variance is usually several times larger than the variance forced by the atmosphere alone. Frankignoul (1981) demonstrated that this was the case for anomaly variability between periods of about 2 months and 1 year by analyzing the Panulirus hydrographic data near Bermuda. He also demonstrated that eddy forcing by horizontal heat advection could account for the additional anomaly variance. Halliwell et al. (1991a) verified that stochastic atmospheric forcing in the Sargasso Sea STCZ is far too small to generate the westward-propagating $T_{s}$ anomaly features observed there. This observation, combined with the observed coupling between anomalies and eddies, allows us to neglect the influence of stochastic atmospheric forcing and analyze the anomaly response to horizontal eddy heat advection alone.

\section{c. Eddy forcing of anomalies in the STCZ}

The following heat balance model will be analyzed:

$$
\frac{\partial T_{s a}^{\prime}}{\partial t}+\lambda T_{s a}^{\prime}=-\frac{g \bar{T}_{s y}}{f} \eta_{x}^{\prime},
$$

where it has been assumed that $v_{g}$ is in geostrophic balance with elevation anomaly slope. Here $T_{s a}^{\prime}$ and $\eta^{\prime}$ are used to focus on eddy variability that can be statistically resolved within the analysis domain.

Zonal-time Fourier transformation of the model (6) yields the following equations for the predicted zonal- 
time autospectrum of $T_{s a}^{\prime}$, and for the gain and phase of the transfer function of the $T_{s a}^{\prime}$ response:

$$
\begin{aligned}
& S_{T T}(k, \omega)=\left(\frac{k^{2}}{\lambda^{2}+\omega^{2}}\right) \alpha^{2} S_{\eta \eta}(k, \omega), \\
& G_{\eta T}(k, \omega)=\frac{\alpha|k|}{\left(\lambda^{2}+\omega^{2}\right)^{1 / 2}},
\end{aligned}
$$

and

$$
\Theta_{\eta T}=\tan ^{-1}\left(\frac{\lambda}{\omega}\right),
$$

where $S_{T T}$ and $S_{\eta \eta}$ are the zonal-time autospectra of $T_{s a}^{\prime}$ and $\eta^{\prime}, k$ and $\omega$ are zonal wavenumber and frequency, and

$$
\alpha=\frac{g \bar{T}_{s y}}{f} .
$$

In the following tests, we use $\bar{T}_{s y}=6 \times 10^{-6}{ }^{\circ} \mathrm{C} \mathrm{m}^{-1}$ and $\lambda=42 \mathrm{yr}^{-1}$. The estimate of $\widetilde{T}_{s y}$ is representative of the winter mean meridional gradient at $28.5^{\circ} \mathrm{N}$ zonally averaged across the analysis domain. The method used to estimate $\lambda$ will be discussed later.

The model is tested using zonal-time spectrum analysis (Pratt 1976 ) at $28.5^{\circ} \mathrm{N}$ (Fig. 6). Raw spectrum estimates were band averaged over two adjacent $k$ bands and three adjacent $\omega$ bands to produce smoothed estimates for bands centered at wavelengths of \pm 1960 , $\pm 660, \pm 390$, and $\pm 280 \mathrm{~km}$ and at periods of 350,233 , $175,140,117,100$, and 88 days. Band averaging was performed over only two adjacent $k$ bands to preserve resolution and to center one of the resulting $k$ bands (wavelength of $660 \mathrm{~km}$ ) as close as possible to the dominant $\sim 800-\mathrm{km}$ wavelength of the eddy-forced anomalies. The resolution of the smoothed spectra is rather poor, with every second $k$ band and every third $\omega$ band statistically independent. Prewhitening was not required in the zonal wavenumber domain because largescale trends have been removed from $T_{s a}^{\prime}$ and $\eta^{\prime}$.

Before proceeding with the analysis, limitations on the space scales that can be resolved in the $\eta^{\prime}$ maps imposed by the Geosat sampling pattern must be discussed. Variance density in the $\eta^{\prime}$ autospectrum in Fig. 6 falls off more rapidly with imcreasing $|k|$ than expected near the largest $|k|$ resolved. Wavenumber autospectra of elevation anomaly along Geosat tracks in the domain from $20^{\circ}-30^{\circ} \mathrm{N}, 70^{\circ}-60^{\circ} \mathrm{W}$ estimated by Le Traon et al. (1990) show that a sharp bend in the spectra occurs near a wavelength of $500 \mathrm{~km}$, with a relatively white spectrum existing at larger wavelengths and $a-3$ slope in the log-log plots existing at smaller wavelengths. However, the rate of decrease of $\eta^{\prime}$ variance density between wavelengths of 390 and $280 \mathrm{~km}$ observed here is about three times larger than expected for $a-3$ slope. Since ascending tracks only were used,

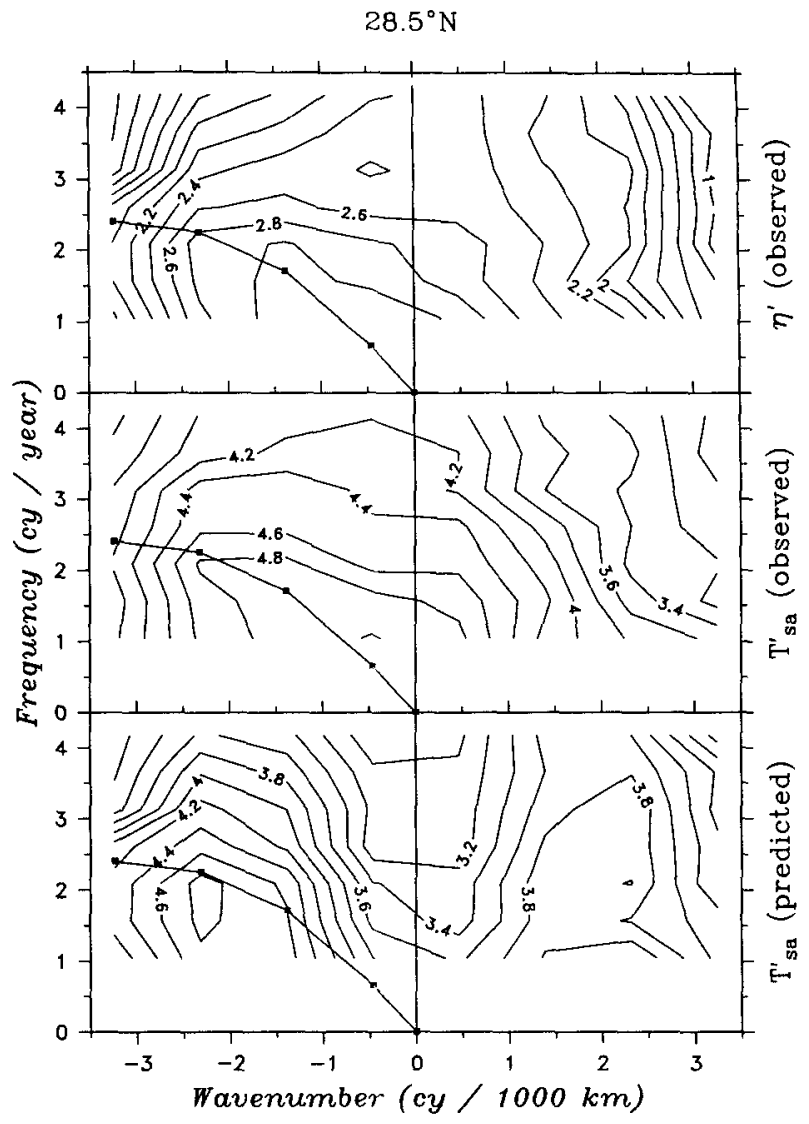

Fig. 6. Observed zonal-time autospectra of $\eta^{\prime}$ (top) and $T_{s a}^{\prime}$ (middle), and predicted zonal-time autospectrum of $T_{s a}^{\prime}$ (bottom), at $28.5^{\circ} \mathrm{N}$. The base 10 logarithm of the energy density is contoured. Observed autospectra were calculated from two-dimensional Fourier transforms of the zonal-time data matrices. Band averaging was performed over three adjacent frequency bands and two adjacent wavenumber bands as described in the text. Given 12 degrees of freedom, the $95 \%$ confidence limits at each $(k, \omega)$ range from the estimate minus 0.29 to the estimate plus 0.44 . The predicted autospectrum was calculated from (7). A dispersion curve for the first baroclinic Rossby wave mode is shown in each panel. The solid squares along the curve in this and subsequent figures mark the center of wavenumber bands resolved in the observed autospectra.

the effective zonal Nyquist wavelength is about 260 $\mathrm{km}$ at $28.5^{\circ} \mathrm{N}$. The spectrum estimates at a wavelength of $280 \mathrm{~km}$ represent an average over bands centered at wavelengths of 330 and $240 \mathrm{~km}$, the latter smaller than the Nyquist wavelength. Since the amplitude of eddies with wavelengths close to the Nyquist is apparently underestimated in our elevation anomaly maps, we will primarily emphasize eddy properties in the wavenumber bands centered at wavelengths of 1960 , 660 , and $390 \mathrm{~km}$ in the ensuing discussion.

A ridge of large $\eta^{\prime}$ variance density exists on the $-k$ side of the zonal-time autospectrum (Fig. 6), roughly following the dispersion curve of the first baroclinic Rossby wave mode calculated for meridional wave- 
number $l=0$ and a radius of deformation estimate obtained from Emery et al. (1984). The use of $l=0$ is justified because meridional propagation of $\eta^{\prime}$ variability could not be detected in meridional-time autocorrelation functions (not shown). The resolution of the $\eta^{\prime}$ autospectrum is far too coarse to detect whether multiple baroclinic modes are present. We now consider whether barotropic Rossby wave energy could be influencing the $\eta^{\prime}$ autospectrum. Unless the phase propagation of barotropic Rossby waves has a substantial meridional component, the frequency of barotropic waves with wavelengths of several hundred kilometers will substantially exceed the largest frequency

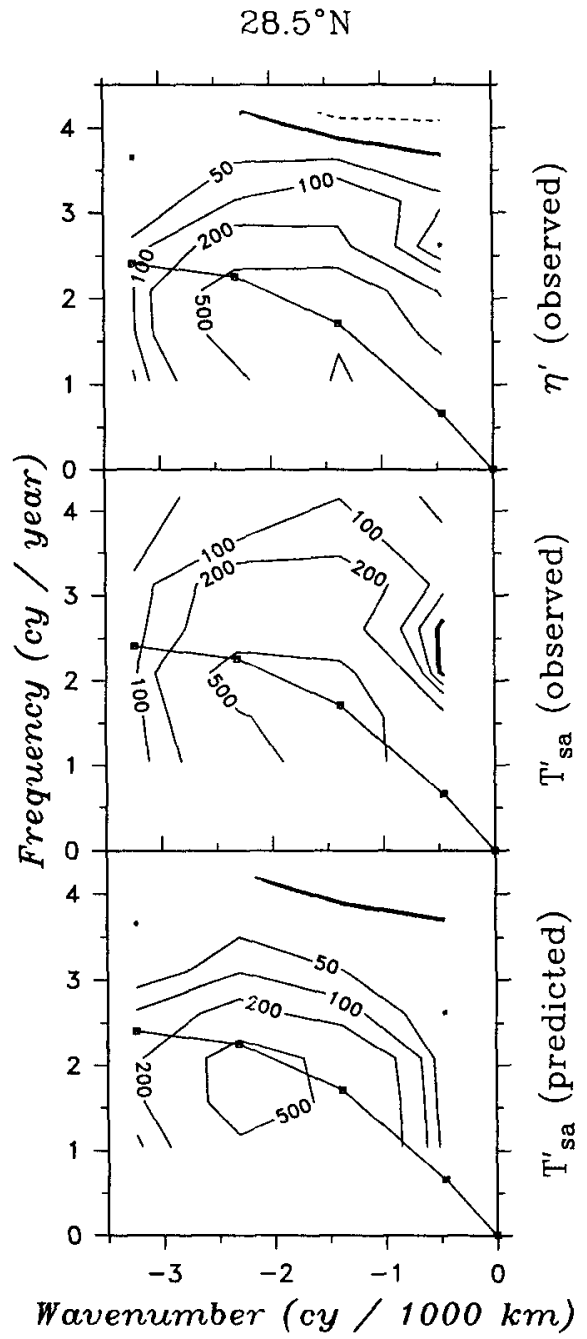

FIG . 7. Zonal-time propagating autospectra at $28.5^{\circ} \mathrm{N}$ calculated from the autospectra graphed in Fig. 6 by subtracting the positive wavenumber side from the negative wavenumber side. Positive values indicate an excess of westward-propagating variance. Shown are the observed propagating autospectra of $\eta^{\prime}$ (top) and $T_{s a}^{\prime}$ (middle), and the predicted propagating autospectrum of $T_{s a}^{\prime}$ (bottom). Both $T_{s a}^{\prime}$ spectra have been divided by 100 . A dispersion curve for the first baroclinic Rossby wave mode is shown in each panel. resolved in Fig. 6. Since meridional propagation of $\eta^{\prime}$ variability could not be detected, it is therefore unlikely that barotropic Rossby wave energy is being detected in the $\eta^{\prime}$ autospectrum in Fig. 6. However, barotropic Rossby wave energy has been detected in a larger region of the western North Atlantic using Geosat data in a study designed specifically to detect those waves (Gaspar and Wunsch 1989).

In the observed autospectrum of $T_{s a}^{\prime}$ at $28.5^{\circ} \mathrm{N}$ (Fig. 6 ), variance density is again relatively large within a ridge that tends to follow the first-mode baroclinic Rossby wave dispersion curve, indicative of the coupling that exists between $\eta^{\prime}$ and $T_{s a}^{\prime}$ at this latitude. The predicted autospectrum of $T_{s a}^{\prime}$ (Fig. 6) was calculated from the observed autospectrum of $\eta^{\prime}$ using (7). For wavelengths exceeding several hundred kilometers, predicted variance density decreases with increasing wavelength while observed variance density does not. The predicted decrease occurs primarily because the effectiveness of forcing by horizontal geostrophic currents in the model (6) decreases with increasing wavelength given a constant magnitude of $\eta^{\prime}$ fluctuations. The predicted anomaly response theoretically goes to zero as $|k|$ goes to zero from (8), although the predicted autospectrum graphed in Fig. 6 does not reach zero because $k=0$ is not a resolved wavenumber. Since the observed variance density does not decrease with increasing wavelength, atmospheric forcing is probably dominant at large wavelengths.

Propagating autospectra were calculated from the three autospectra in Fig. 6 by subtracting the variance density at negative $k$ from the variance density at positive $k$, and they therefore represent the excess of westward-propagating variance over eastward-propagating variance (Pratt 1976). The three propagating autospectra are graphed in Fig. 7 as a function of $-k$ and $\omega$ so that the functions can be compared to the Rossby wave dispersion curves. Variance density due to standing waves and white noise do not contribute to propagating autospectra. In the present case, propagating autospectra are especially useful because at the low frequencies of the eddies and anomalies, atmospheric variability does not have a preferred zonal propagation direction (Willebrand 1978) and neither does the anomaly field forced by the atmosphere (Halliwell et al. 1991a). Consequently, the observed propagating autospectrum of $T_{s a}^{\prime}$ should be dominated by eddyforced anomalies. This is confirmed by the propagating autospectra in Fig. 7. A large excess of westward-propagating $\eta^{\prime}$ variance density roughly follows the firstmode baroclinic Rossby wave dispersion curve as expected. The observed and predicted propagating autospectra of $T_{s a}^{\prime}$ are much more similar in structure than the corresponding autospectra in Fig. 6 . In both functions, westward-propagating variance density is largest for wavelengths of 660 and $390 \mathrm{~km}$ at frequencies near the dispersion curve, and decreases with in- 
creasingly large wavelength as the eddy influence diminishes. The most noticeable difference between the two functions is that the observed excess of westwardpropagating variance density decreases less rapidly with increasing frequency than the predicted excess for frequencies above the dispersion curve.

The squared coherence between the $\eta^{\prime}$ and $T_{s a}^{\prime}$ fields at $28.5^{\circ} \mathrm{N}$ (Fig. 8) exceeds 0.8 in the $-k$ side of $(k, \omega)$ space at wavelengths of 390 and $660 \mathrm{~km}$ near the firstmode baroclinic Rossby wave dispersion curve. This high coherence is remarkable considering that the dataset spans two summer intervals when the $T_{s}$ anomaly response is relatively weak. To quantify the degree to which eddy forcing dominates atmospheric forcing, we include the atmospheric forcing term $F_{a}$ in the model (6), neglect the influence of data noise, then derive the following expression for the squared coherence between $\eta^{\prime}$ and $T_{s a}^{\prime}$ in the presence of both eddy and atmospheric forcing:

$28.5^{\circ} \mathrm{N}$

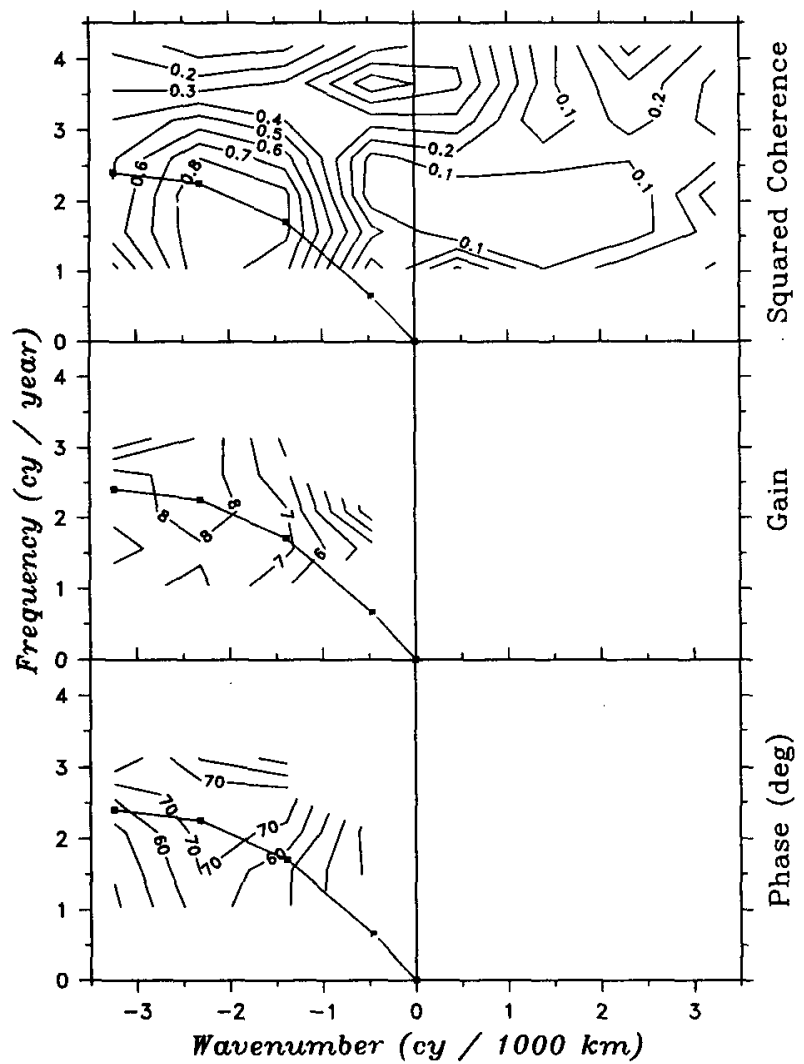

FIG. 8. Observed squared coherence $\gamma^{2}$ between $\eta^{\prime}$ and $T_{s a}^{\prime}$ (top), and observed gain and phase of the transfer function (middle and bottom) at $28.5^{\circ} \mathrm{N}$. Squared coherence exceeding 0.38 is significantly greater than zero to a $95 \%$ level of confidence. Gain and phase are only contoured in that part of $(k, \omega)$ space where squared coherence is high and where variance density due to westward-propagating eddies is large.

$$
\gamma_{\eta T}^{2}(k, \omega)=1 /\left(1+\gamma \frac{S_{F F}(k, \omega)}{S_{\eta \eta}(k, \omega)}\right),
$$

where $S_{F F}$ is the autospectrum of atmospheric forcing. Since noise in the data will tend to reduce the value of observed $\gamma^{2}$ between $\eta^{\prime}$ and $T_{s a}^{\prime}$, it will lead to an overestimate of the ratio $S_{F F} / S_{\eta \eta}$. Consequently, observed $\gamma^{2}$ cannot be used in (11) to accurately estimate this ratio, but it can be used to estimate an upper bound on this ratio as a function of $|k|$ and $\omega$. In the region of $(k, \omega)$ space where $\gamma^{2}>0.8, S_{\eta \eta}$ must exceed $S_{F F}$ by at least a factor of four. At wavelengths of $390 \mathrm{~km}$ and periods of 175 days, where the maximum $\gamma^{2}$ of 0.90 is observed, $S_{\eta \eta}$ must exceed $S_{F F}$ by at least a factor of nine. The dominance of eddy forcing over atmospheric forcing in this region of $(k, \omega)$ space is thus confirmed. The rapid decrease in $\gamma^{2}$ with increasing wavelength at large wavelengths presumably results largely because $S_{F F} / S_{\eta \eta}$ increases as the effectiveness of eddy forcing decreases relative to atmospheric forcing. Here $\gamma^{2}$ also decreases with decreasing wavelength for wavelengths $>390 \mathrm{~km}$, but this is caused at least in part by the Geosat sampling limitations discussed previously. Evidence from MODE indicates that strong coherence between $T_{s}$ anomalies and horizontal eddy currents does extend to smaller wavelengths than resolved here (Voorhis et al. 1976).

The gain and phase of the observed transfer function between $\eta^{\prime}$ and $T_{s a}^{\prime}$ at $28.5^{\circ} \mathrm{N}$ are graphed in Fig. 8 within that region of $(k, \omega)$ space where both fields are relatively energetic and highly coherent (near the dispersion curve). The gain and phase of the predicted transfer function were first calculated from (8) and (9) using $\lambda=7 \mathrm{yr}^{-1}$ obtained from Reynolds (1979), a magnitude that has proven to be realistic for describing properties of $T_{s}$ anomalies driven soley by stochastic atmospheric forcing (e.g., Frankignoul and Hasselmann 1977; Reynolds 1979; Frankignoul and Reynolds 1983). However, a much larger value of $\lambda\left(42 \mathrm{yr}^{-1}\right)$ was required to make the predicted gain and phase (Fig. 9) resemble the observed functions (Fig. 8) in the present eddy-forced model. The predicted increase of gain with decreasing wavelength exists in the observed gain function except near the largest $|k|$ resolved, where Geosat sampling limitations probably degrade the results. Predicted phase decreases slowly with frequency, but this small decrease cannot be detected in the observed phase. The large value of $\lambda$ that was required indicates that the dominant balance in the model (6) is between the eddy forcing and damping terms at the scales resolved in the present study. Perhaps the large $\lambda$ is compensating for neglected processes such as horizontal eddy diffusion.

There are several factors that act to degrade the quality of the results presented here, including the assumption of constant $h$ and the neglect of vertical heat flux anomalies at the mixed-layer base driven by the 


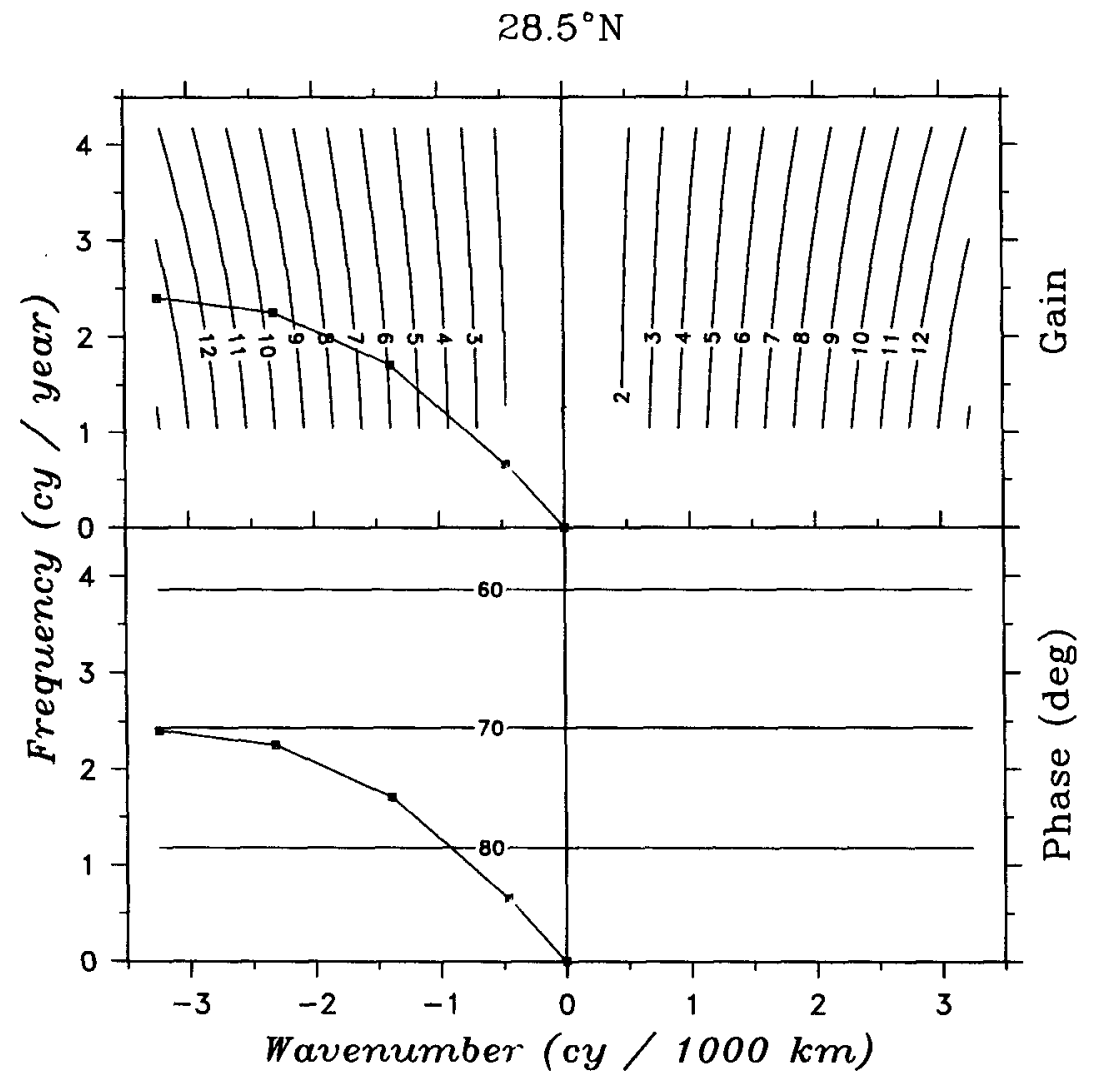

FIG. 9. Gain and phase of the transfer function (middle and bottom) at $28.5^{\circ} \mathrm{N}$ predicted by the model (6) calculated using (8) and (9). A dispersion curve for the first baroclinic Rossby wave mode is shown in each panel.

eddies (e.g., Stevenson 1983) through terms involving $w_{e}$ in (2). Another potential limitation is the fact that the AVHRR measures a skin temperature at the ocean surface, not the desired bulk mixed-layer temperature. The algorithm used to calculate $T_{s}$ from AVHRR measurements (e.g., McClain et al. 1985) has been tuned to represent bulk temperature, but this algorithm does not account for spatial, temporal, or regional variability in the skin-bulk temperature difference. Fortunately, a recent study (Schluessel et al. 1990) has determined that skin and bulk temperature is highly coherent over the range of wavelengths resolved in the present study, so this problem probably did not seriously degrade the analysis results. Thus, we conclude that horizontal eddy currents are the dominant forcing mechanism for the westward-propagating $T_{s}$ anomalies observed in the STCZ.

\section{Meridional variability}

\section{a. Zonal eddy dispersion}

Zonal-time propagating autospectra of $\eta^{\prime}$ at five latitudes are used to illustrate the meridional variability of zonal eddy dispersion properties (Fig. 10). The propagating autospectrum at $29.5^{\circ} \mathrm{N}$, the latitude that has the largest total excess of westward-propagating variance, represents zonal dispersion properties in the STCZ. The structure of this propagating autospectrum is very similar to the one at $28.5^{\circ} \mathrm{N}$ (Fig. 7), with positive (westward-propagating) variance density concentrated near the first-mode Rossby wave dispersion curve. The percentage of variance density propagating westward (Fig. 11) exceeds $70 \%$ throughout this region of $(k, \omega)$ space, and it is close to or exceeds $90 \%$ for wavelengths of 390 and $660 \mathrm{~km}$ at periods $>200$ days.

Propagating autospectra north and south of the STCZ differ substantially from this pattern (Fig. 10). In the propagating autospectrum south of the STCZ $\left(23.5^{\circ} \mathrm{N}\right)$, the ridge of large positive variance density roughly follows a straight line instead of bending to follow the Rossby wave dispersion curve. This pattern is suggestive of a field of nondispersive eddies propagating westward at about twice the speed observed in the STCZ, in agreement with the increased speed revealed by the slope of the zonal-time autocorrelation function at $22.5^{\circ} \mathrm{N}$ (Fig. 3). Both within and south of 


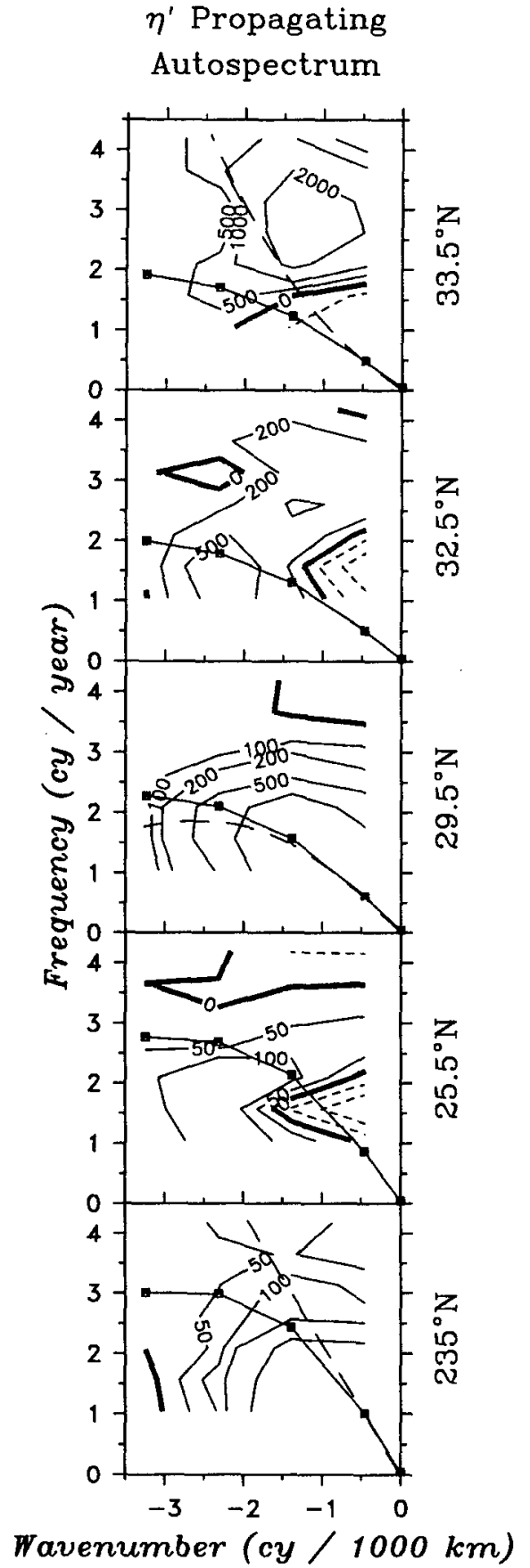

FIG. 10. Observed zonal-time propagating autospectra of $\eta^{\prime}$ at five different latitudes. Dispersion curves for the first baroclinic Rossby wave mode are shown in each panel.

the STCZ, a large excess of westward-propagating variance density is concentrated near the dispersion curve at larger wavelengths $(660$ and $1960 \mathrm{~km})$, suggesting that substantial long-wave energy is present. To the north of the STCZ, however, there is no preferred propagation direction (the propagating autospectrum is not significantly different from zero) in this longwave region of $(k, \omega)$ space. Long-wavelength vari-

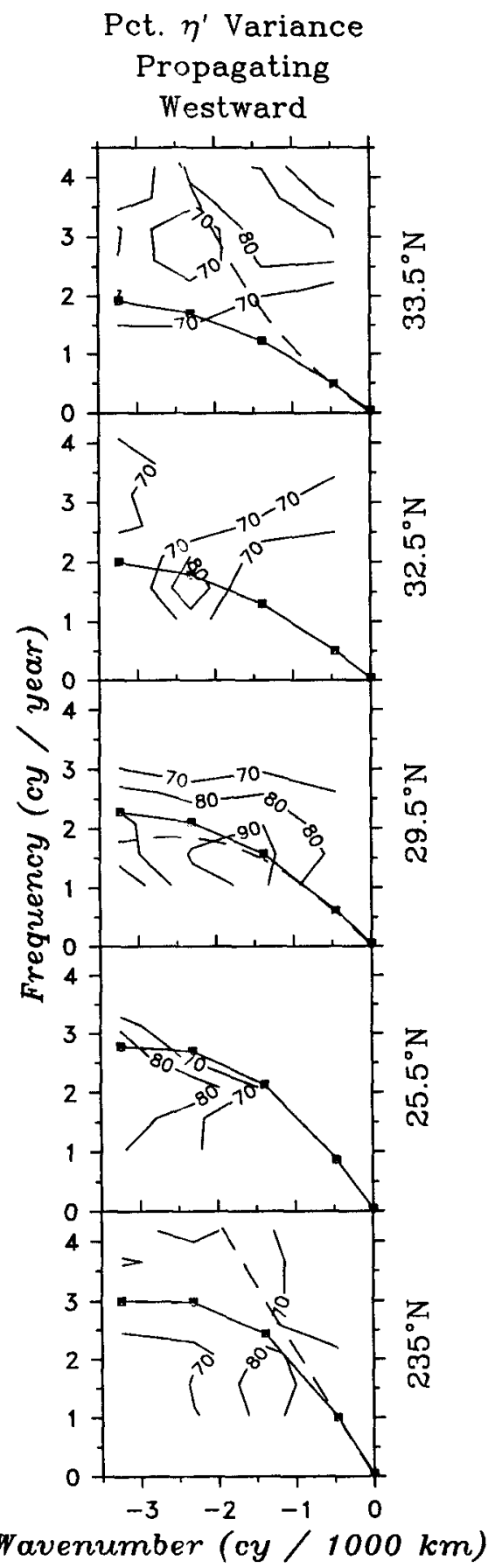

FIG. 11. Percentage of variance density propagating westward in the observed zonal-time autospectra of $\eta^{\prime}$ at the five latitudes corresponding to the propagating autospectra in Fig. 10. In regions where this percentage exceeds $73 \%$, westward-propagating is significantly greater than eastward-propagating variance density to a $90 \%$ level of confidence. Dispersion curves for the first baroclinic Rossby wave mode are shown in each panel. 
ability does exist, but at frequencies 2-3 times larger (at periods near 100 days) than expected for long Rossby waves. The resulting larger westward propagation speed is also suggested by the slope of the zonaltime autocorrelation function at $33.5^{\circ} \mathrm{N}$ (Fig. 3). Both north and south of the STCZ, typically between $70 \%$ and $85 \%$ of the variance density is westward propagating in those regions of $(k, \omega)$ space where a strong westward-propagating signal exists (Fig. 11). Narrow transition zones $1-2$ degrees wide centered at $25.5^{\circ}$ and $32.5^{\circ} \mathrm{N}$ separate these three regions. Propagating autospectra at these latitudes do not resemble the autospectra within the three regions they separate (Figs. 10 and 11 ).

The meridional structure of eddy dispersion properties is also illustrated by graphing both the total variance density (the sum of the $+k$ and $-k$ autospectrum estimates) and the percentage of this total variance density that is westward propagation as a function of latitude. These two functions are graphed for three $(|k|, \omega)$ bands located near the first-mode baroclinic Rossby wave dispersion curve (Fig. 12). Focusing first on the $660-\mathrm{km}, 233$-day band, which corresponds closely to the dominant wavelengths and periods of the $T_{s}$ anomalies and the eddies that force them, westwardpropagating eddy variability is strongly trapped within the STCZ. Over $90 \%$ of the variance is westward propagating near $29.5^{\circ} \mathrm{N}$, and this decreases to about $50 \%$ (no preferred propagation direction) as the transition latitudes are approached (Fig. 12e). This eddy variability is trapped in the same zonal band where the winter mean meridional $T_{s}$ gradient associated with the STCZ is large (Fig. 12a), suggesting a possible connection between the existence and location of the climatological mean subtropical frontal zone and dynamical processes confining this eddy variability to the STCZ. Westward-propagating eddy variability is also observed to the south of the STCZ, with $83 \%$ of vari- ance density propagating westward at $23.5^{\circ} \mathrm{N}$ (Fig. 12e). The meridional trapping is not clearly evident, however, in the graph of total variance density (Fig. 12d). This function is smallest at the southern transition latitude, has a relative maximum at $30^{\circ} \mathrm{N}$ near the central latitude of the $S T C Z$, a relative minimum at the northern transition latitude, and a sharp increase to the north of the STCZ. A sharp increase in eddy energy to the north of $32^{\circ} \mathrm{N}$ was also reported by Ebbesmeyer and Taft (1979) from analyses of historical data.

Similar meridional structure is observed in the 1960$\mathrm{km}, 350$-day band in both total variance density and the percentage propagating westward (Figs. 12b,c). However, the percentage of westward-propagating variance (Fig. 12c) is generally smaller, suggesting that westward-propagating eddies are not as dominant in this $(|k|, \omega)$ band. Eddy variability in the $390-\mathrm{km}$, 175-day band differs from the variability at larger wavelengths because it displays much less meridional variability. The percentage variance propagating westward ranges from $74 \%-88 \%$ north of $26^{\circ} \mathrm{N}$, and decreases to $60 \%-70 \%$ south of the southern transition latitude (Fig. $12 \mathrm{~g}$ ). The total variance density generally decreases in magnitude toward the south to a relative minimum at about $24^{\circ} \mathrm{N}$ (Fig. 12f). A relative minimum in the variance density also exists at the northern transition latitude, but this is not associated with a minimum in the percentage of variance density propagating westward.

\section{b. Anomaly forcing}

The obvious reason for the meridional confinement of strong, persistent westward-propagating $T_{s}$ anomaly features to the STCZ is that the mean meridional $T_{s}$ gradient is relatively large there from fall to spring, making horizontal eddy currents relatively effective at forcing anomalies. However, the meridional confine-

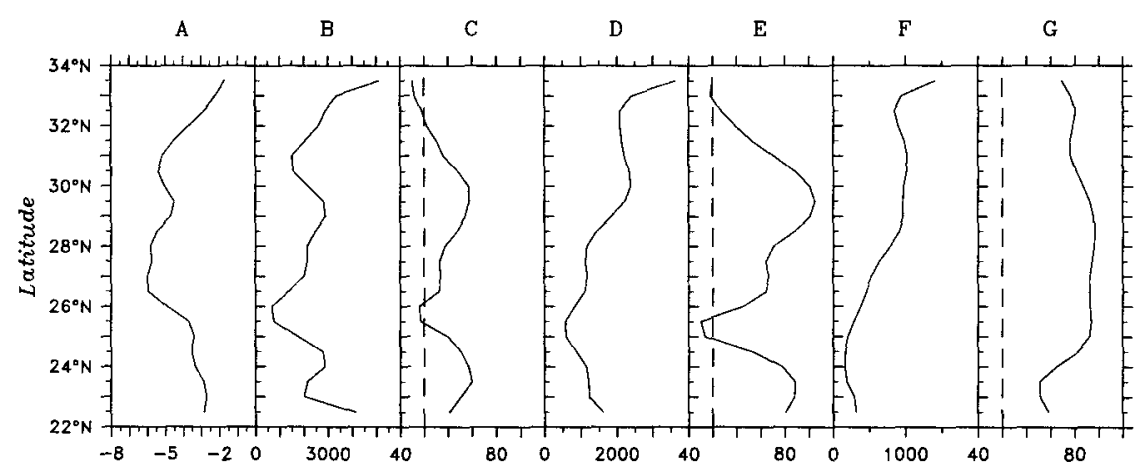

FIG. 12. Mean winter meridional gradient of zonally averaged temperature averaged over the two mid-November through mid-May intervals (A); the total variance density and percentage of variance density propagating westward graphed as a function of latitude in three wavenumberfrequency bands centered at wavelengths and periods of $1960 \mathrm{~km}$ and 350 days (B and C), 660 $\mathrm{km}$ and 233 days ( $D$ and $E$ ), and $390 \mathrm{~km}$ and 175 days ( $F$ and $G$ ). 


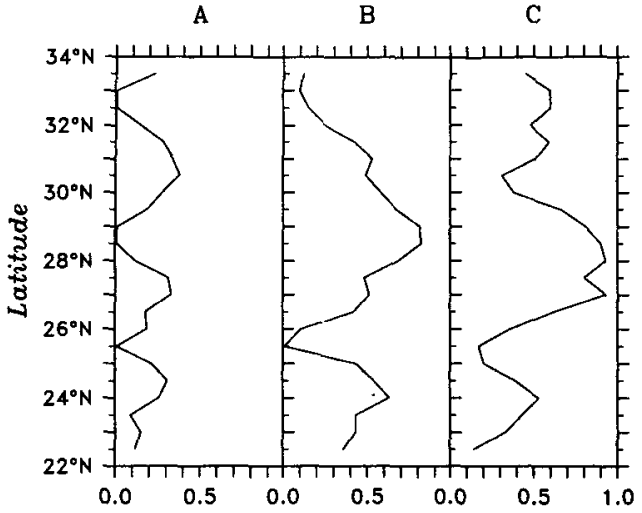

FIG. 13. Squared coherence between $\eta^{\prime}$ and $T_{s a}^{\prime}$ graphed as a function of latitude in the wavenumber-frequency bands centered at wavelengths and periods of $1960 \mathrm{~km}$ and 350 days (A), $660 \mathrm{~km}$ and 233 days (B), and $390 \mathrm{~km}$ and 175 days $(\mathrm{C})$.

ment to the STCZ of the eddies with wavelengths of $\sim 800 \mathrm{~km}$ and periods of $\sim 200$ days that forces these persistent anomalies also contributes to the anomaly confinement. These points are illustrated by examining $\gamma^{2}$ between $\eta^{\prime}$ and $T_{s a}^{\prime}$ as a function of latitude (Fig. 13 ) in the same three wavenumber-frequency bands used in Fig. 12. In the longest wavelength band, the fields are not coherent due to the relative unimportance of eddy forcing. In both the 390-km, 175-day and 660$\mathrm{km}, 233$-day bands, however, coherence is relatively large within the STCZ. Since eddy variability in the $390-\mathrm{km}, 175-$ day band is not strongly confined to the STCZ, the coherence maximum results primarily from the relative effectiveness of anomaly forcing where mean meridional $T_{s}$ gradient is large. In the $660-\mathrm{km}$, 233-day band, both the eddy confinement and the presence of large mean gradient probably contribute to the STCZ coherence maximum. Relatively large coherence is also observed south of the southern transition latitude in this band (Fig. 13), but the anomalies forced there are weak (not shown).

One reason that STCZ anomalies with wavelengths $\sim 800$ and periods $\sim 200$ days stand out above background variability is their long temporal persistence (Halliwell et al. 1991a). They are persistent because the eddies that force them are persistent. In the zonaltime contour plot of $\eta^{\prime}$ at $29.5^{\circ} \mathrm{N}$ (Fig. 14), temporally persistent eddies with wavelengths of $\sim 800 \mathrm{~km}$ and periods of $\sim 200$ days stand out and visually resemble a propagating wave train. These wavelike features are not as clearly evident during the first six months of the two-year interval at $29.5^{\circ} \mathrm{N}$, but wavelike features with similar dominant wavelengths and periods were evident then at $28^{\circ} \mathrm{N}$ (Fig. 15). Persistent, wavelike eddies were thus present during the entire two-year interval, but interannual variability apparently exists in the latitude where this signal is centered. The persistence of these eddies and the anomalies they force contributes to the dominance of the $800-\mathrm{km}$ wavelength, 200-day period in the zonal-time correlation functions at $28.5^{\circ} \mathrm{N}$ (Fig. 3 ). Eddy variability with wavelengths near $390 \mathrm{~km}$ was also very coherent with $T_{s a}^{\prime}$ fluctuations (Fig. 8), but the large persistence of the $800-\mathrm{km}$ wavelength variability helped produce the dominance of these larger scales in the correlation functions. The tendency for correlation functions to emphasize larger-wavelength, longer-period variability also contributed to this dominance.

\section{Eddy dynamics}

We now consider dynamical processes responsible for the observed spatial variability of zonal eddy dispersion properties. We first perform a simple test to determine if the interaction between the baroclinic eddy and mean current fields can explain some of this spatial variability. We then briefly spectulate on dynamical processes that may be responsible for the existence and

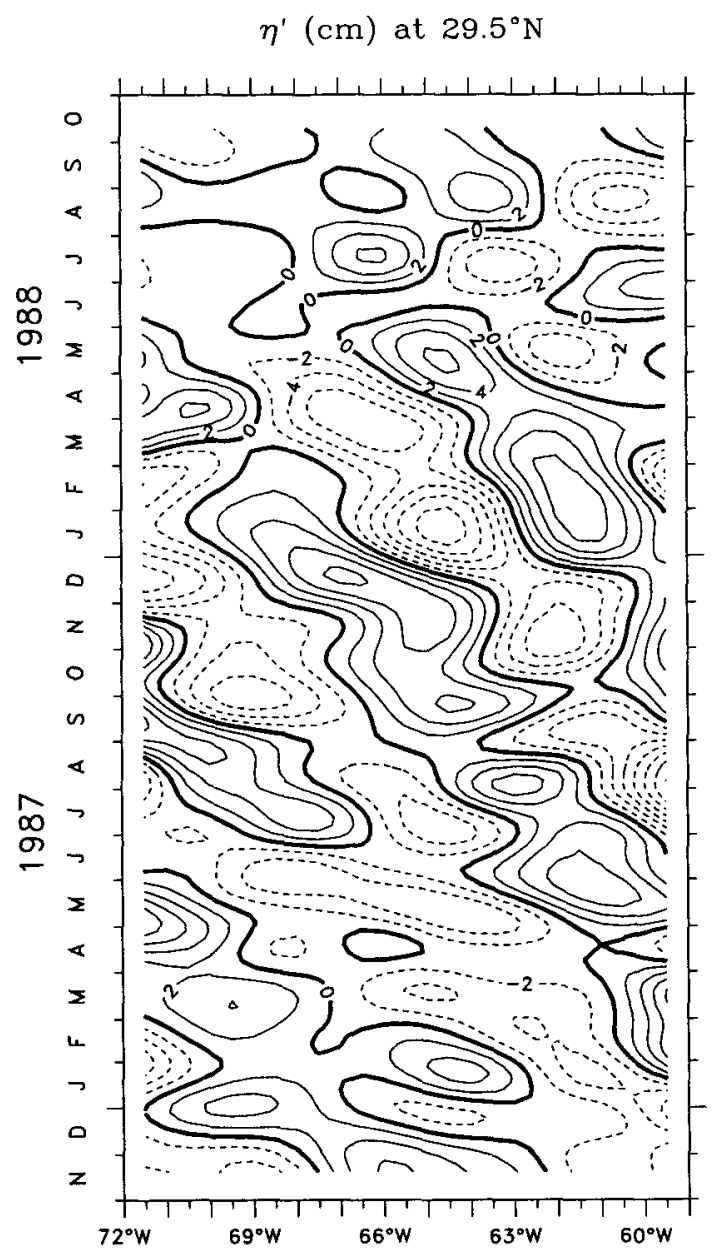

FIG. 14. Zonal-time contour plot of $\eta^{\prime}$ at $29.5^{\circ} \mathrm{N}$. 


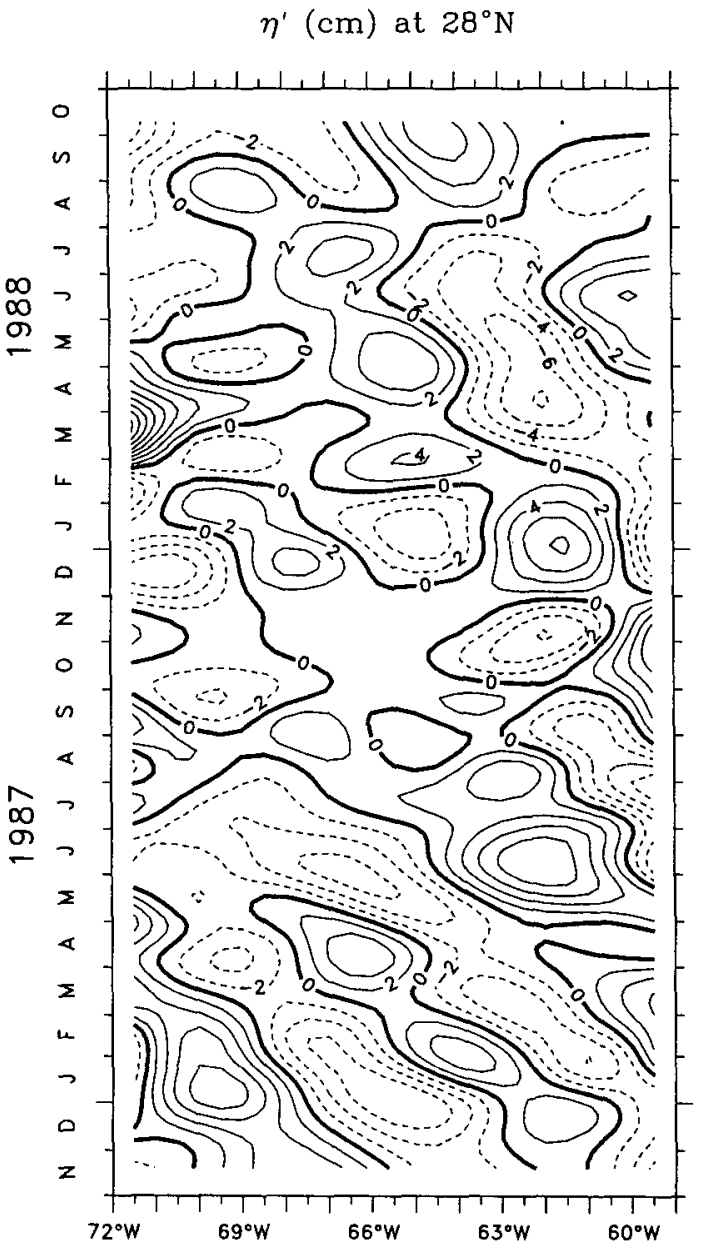

Fig, 15. Zonal-time contour plot of $\eta^{\prime}$ at $28^{\circ} \mathrm{N}$.

meridional confinement of the wavelike eddy variability observed in the STCZ.

A fundamental consideration for modeling eddy variability is the relative importance of wave and nonlinear dynamics. A transition wavenumber below which wave dynamics becomes dominant over nonlinear dynamics has been derived (e.g., Killworth 1979; Haidvogel 1983), and it is given by

$$
k_{T} \approx(\beta / 2 U)^{1 / 2} .
$$

Using a characteristic eddy rms amplitude of $\approx 0.1 \mathrm{~m}$ $\mathrm{s}^{-1}$ to represent $U$ in this region, the transition wavelength is about $600-700 \mathrm{~km}$. Thus, wave dynamics are expected to be important for eddy variability at the two largest wavelengths (660 and $1960 \mathrm{~km})$ resolved in the zonal-time spectrum analysis (section 4). Consequently, linearized models of the interaction between Rossby waves and mean current may be adequate to account for some of the observed meridional variability in zonal dispersion properties observed at these larger wavelengths. In contrast, the smaller-wavelength eddies resolved during earlier experiments such as MODE are significantly more nonlinear (MODE Group 1978).

Perhaps the simplest such model that can be tested is the reduced-gravity model of a dynamically active layer overlaying a dynamically inactive layer. Given a zonal mean current $\bar{U}$ in the upper layer, the linearized governing quasi-geostrophic wave equation for this layer is

$$
\left(\nabla_{H}^{2}-a^{-2}\right) \eta_{t}+\left(\beta+\bar{U} \nabla_{H}^{2}\right) \eta_{x}=0,
$$

where $a=\left(g^{\prime} H\right)^{1 / 2} / f$ is the Rossby radius of deformation. The resulting Rossby wave dispersion relation is

$$
\omega=\frac{-\left[\beta-\bar{U}\left(k^{2}+l^{2}\right)\right] k}{k^{2}+l^{2}+a^{-2}} .
$$

A dynamical discussion of this model is presented in Kessler (1990).

Although predominantly westward mean flow is expected to exist in the analysis domain based on simple subtropical gyre models, eastward current shear is known to exist within a zonal band a few degrees of latitude wide in the Sargasso Sea. Dynamic topography maps presented in Stommel et al. (1978), Reid (1978), Ebbesmeyer and Taft (1979), and Olson et al. (1984), along with analyses of the meridional variability of isotherm depths across the subtropical gyre (Williams and Olson 1982), all show that mean eastward current shear (positive $\Delta \bar{U} / \Delta z$ ) exists above the main thermocline in a zonal band near the STCZ. SOFAR floats deployed in the main thermocline near $700 \mathrm{~m}$ in the STCZ have often revealed eastward flow (Rossby et al. 1983), suggesting that the mean current is occasionally eastward both within and above the main thermocline. Current moorings in the western North Atlantic at $28^{\circ} \mathrm{N}$ have also consistently revealed eastward mean current in the upper ocean (Richman et al. 1977; Schmitz 1978; Brink 1989), although the statistical significance of mean currents obtained from individual mooring deployments is marginal. This eastward baroclinic current may be analogous to the subtropical countercurrent observed in the western North Pacific (e.g., Uda and Hasunuma 1969).

The influence of mean currents on first-mode baroclinic Rossby wave dispersion curves predicted by (14) assuming $l=0$ is illustrated at three latitudes in Figs. 10 and 11 . At $29.5^{\circ} \mathrm{N}$, assuming $\bar{U}=0.02 \mathrm{~m} \mathrm{~s}^{-1}$ eastward in the active upper layer, the mean current shifts the dispersion curve toward lower frequency for wavelengths less than a few hundred kilometers (Fig. 10). The curve predicted from (14) asymptotically approaches the curve predicted in the absence of mean current for increasing wavelength, which is an intrinsic property of the reduced-gravity model as discussed by 
Kessler (1986). Although the shift in the dispersion curve at $29.5^{\circ} \mathrm{N}$ is too small to be resolved by the coarse-resolution propagating autospectrum of $\eta^{\prime}$, the large change in zonal dispersion properties between the STCZ and the region to the south can be qualitatively explained by this model. If a westward mean current of $0.05 \mathrm{~m} \mathrm{~s}^{-1}$ is assumed to exist at $23.5^{\circ} \mathrm{N}$, the dispersion curve predicted from (14) becomes a nearly straight line that follows the ridge of large variance density in the propagating autospectrum (Fig. 10). However, this model cannot account for the zonal dispersion properties north of the STCZ. Assuming a rather large mean current of $0.1 \mathrm{~m} \mathrm{~s}^{-1}$ westward at $33.5^{\circ} \mathrm{N}$, the predicted zonal dispersion curve is not sufficiently displaced toward higher frequencies to account for the energy density maximum (Fig. 10). Other dynamical processes must be important there, such as instability mechanisms or radiation of wave energy from the Gulf Stream and its rings.

Although this test does not prove the validity of the model (13), it is capable of explaining some, but not all, of the observed meridional variability of zonal eddy dispersion properties. This model is far too simple, however, to capture all of the essential physics responsible for this observed meridional variability. For example, the single-layer reduced-gravity model cannot reproduce the influence of the complex mean threedimensional density structure that actually exists in the STCZ, where the main thermocline tends to deepen and the seasonal thermocline tends to shoal toward the north. This tendency for the two thermoclines to separate is related to the thickneing of the Subtropical Mode Water layer toward the north. Consequently, multilayered or continuously stratified models, such as the quasigeostrophic continuously stratified model described by Gill et al. (1974) and Kang et al. (1982), should be investigated.

We now consider the existence of the wavelike eddies and their confinement to the STCZ. Their relatively wavelike appearance may simply result because nonlinear effects are less important for these eddies than for smaller-wavelength eddies. However, processes responsible for their generation and maintenance, for the dominance of wavelengths near $800 \mathrm{~km}$ and periods near 200 days, and for their confinement to the STCZ will require further study and is beyond the scope of the present paper. Processes that must be considered include instability of the mean current and the refraction of eddy (Rossby wave) variability. If eddy variability arises due to an instability mechanism, it is possible that the energy cascade toward larger wavelengths is arrested by the increasing dominance of wave dynamics at wavelengths of several hundred kilometers (e.g., Rhines 1975; Killworth 1979), thus generating the wavelike features at these wavelengths. Alternatively, the existence of mean currents modifies the refraction of Rossby wave rays, which can concentrate wave energy in discrete latitude bands bounded by turning latitudes and by critical latitudes where wave energy is absorbed (Chang 1990; Chang and Philander 1990).

\section{Summary and conclusions}

Persistent, relatively wavelike baroclinic eddies with a wavelength of $\sim 800 \mathrm{~km}$, period of $\sim 200$ days, and westward propagation speed of 3-4 $\mathrm{km}^{-1 a y}{ }^{-1}$ are responsible for the existence of the energetic, persistent westward-propagating $T_{s}$ anomaly features observed in the Sargasso Sea by Halliwell and Cornillon (1989) and Halliwell et al. (1991a). The anomaly features were coupled to the eddies in zonal-time space with a phase lag qualitatively consistent with forcing by horizontal eddy currents. Tests of a simple anomaly heat balance model forced by horizontal eddy currents and damped by a linear feedback mechanism confirmed that eddy forcing by horizontal currents could account for the magnitude and negative temporal phase lag of the anomaly response. This simple model did not capture all of the physics of anomaly forcing since many simplifications, including the neglect of forcing by the influence of eddies on vertical heat flux at the mixedlayer base, were made. An unexpectedly large damping coefficient had to be used, possibly compensating in part for the neglect of horizontal diffusion.

The westward-propagating $T_{s}$ anomalies were confined between about $26^{\circ}$ and $32^{\circ} \mathrm{N}$ (Halliwell et al. 1991a), the approximate latitude band within which the enhanced meridional $T_{s}$ gradients associated with the mean subtropical frontal zone were confined. Thus, a primary reason for anomaly confinement was that horizontal eddy currents forced relatively strong anomalies due to the large mean $T_{s}$ gradients within the frontal zone. However, meridional variability in properties of the baroclinic eddy field also contributed to anomaly confinement. Baroclinic eddy variability with the zonal wavelengths and periods of the $T_{s}$ anomalies was also confined to the STCZ, and eddies with these zonal wavelengths and periods had much longer temporal persistence scales than eddy variability both outside of the STCZ and within the STCZ at different wavelengths and periods. The long temporal persistence of the anomaly features forced by these eddies made them stand out visually and statistically above the noise.

An attempt was made to determine dynamical processes responsible for the observed meridional variability of eddy properties. Although simple models of subtropical gyres predict predominantly westward mean flow in the latitude range of the Sargasso Sea STCZ, a zonal band of mean eastward current shear in the upper ocean is known to exist in the Sargasso Sea near these latitudes that separates regions where westward mean flow dominates. A simple reduced- 
gravity model could qualitatively account for the observed change in zonal eddy dispersion between the STCZ and the region to the south under the assumption that the upper ocean current is eastward in the STCZ and westward to the south. However, this model could not explain zonal dispersion properties north of the STCZ in the relatively strong, predominantly westward flow in Gulf Stream recirculation region, possibly because other physical processes such as instabilities or wave radiation from the Gulf Stream or its rings may be important there.

At large scales, subtropical gyres have been characterized as smooth features within which horizontal variability in mesoscale eddy properties is relatively small. For example, a broad relative minimum in both eddy potential and eddy kinetic energy exists throughout the central regions of the North Atlantic subtropical gyre (e.g., Dantzler 1977; Ebbesmeyer and Taft 1979; Emery 1983; Richardson 1983). However, a rich meridional structure in eddy properties was found in the present study to exist within this supposedly smooth region, with large changes in properties occurring over meridional distances of 1-2 degrees of latitude. This structure was also not detected in recent studies of eddy/Rossby wave properties conducted by analyzing Geosat data within $10^{\circ}$ by $10^{\circ}$ regions (Le Traon et al. 1990; Jacobs et al. 1990). At least within oceanic frontal zones, studies should be designed to detect changes in eddy properties in the cross-front direction, and also should be designed with the realization that eddies can be significantly anisotropic in these regions. Interannual variability of eddy properties may also be significant in frontal zones. For example, it is possible that the differences in the statistical properties of time series of currents measured at the MODE site between the 1970s and 1980s (Schmitz 1978, 1989) could be partly explained by interannual variability in the strength and latitude of the subtropical frontal zone (and the resulting changes in the mean current pattern) and the resulting changes in eddy properties.

Acknowledgments. This research was performed with the support of the Office of Naval Research (No. N00014-87-KT0235) as part of the Frontal Air-Sea Interaction Experiment, and of the National Aeronautics and Space Administration (No. 957627). All figures were generated using the interactive graphics package PLOT5, developed by Dr. Donald Denbo. The image processing software was developed by R. Evans, O. Brown, J. Brown, and A. Li at the University of Miami under Office of Naval Research funding. The continuing support of the Miami group is gratefully acknowledged. The manuscript was extensively revised at RSMAS, and the author gratefully acknowledges transitional support provided under grants from NASA (NAGW-273, NAGW-678, and NASS-30557) and ONR (N00014-89-J-1144).
REFERENCES

Bisagni, J. J., 1989: Wet tropospheric range corrections for satellite altimeter-derived dynamic topographies in the western North Atlantic. J. Phys. Oceanogr., 94, 3247-3254.

Brink, K. H., 1989: Evidence for wind-driven current fluctuations in the western North Atlantic. J. Geophys. Res., 94, 2029-2044.

Carter, E. F., and A. R. Robinson, 1987; Analysis models for the estimation of oceanic fields. J. Atmos. Oceanic Technol., 4, 4974.

Chang, P., 1990: Oceanic adjustment in the presence of mean currents on an equatorial $\beta$ plane. J. Geophys. Res., 95, 15 975-15996.

_-, and S. G. H. Philander, 1990: Rossby wave packets in baroclinic mean currents. Deep-Sea Res., 36, 17-37.

Dantzler, H. L., Jr., 1977: Potential energy maxima in the tropical and subtropical North Atlantic. J. Phys. Oceanogr., 7, 512-519.

Ebbesmeyer, C. C., and B. A. Taft, 1979: Variability of potential energy, dynamic height, and salinity in the main pycnocline of the western North Atlantic. J. Phys. Oceanogr., 9, 1073-1089.

Emery, W. J., 1983: On the geographical variability of the upper level mean and eddy fields in the North Atlantic and North Pacific. J. Phys. Oceanogr., 13, 269-291.

- W. G. Lee and L. Magaard, 1984: Geographic and seasonal distributions of Brunt-Väisälä frequency and Rossby radii in the North Pacific and North Atlantic. J. Phys. Oceanogr., 14, 294-317.

Frankignoul, C., 1981: Low-frequency temperature fluctuations off Bermuda. J. Geophys. Res., 86, 6522-6528.

air-sea feedback in the middle latitudes. Rev. Geophys., 23, 357390.

plication to sea surface temperature variability and thermocline variability. Tellus, 29, 284-305.

mid-latitude sea-surface temperature anomalies. $J$. Phys. Oceanogr., 13, 1131-1145.

Gaspar, P., and C. Wunsch, 1989: Estimates from altimeter data of barotropic Rossby waves in the northwestern Atlantic Ocean. J. Phys. Oceanogr., 19, 1821-1844.

Gill, A. E., J. S. A. Green, and A. J. Simmons, 1974: Energy partition in the large-scale ocean circulation and the production of midocean eddies. Deep-Sea Res., 21, 499-528.

Haidvogel, D. B., 1983: Periodic and regional models. In Eddies in Marine Science, A. R. Robinson, Ed., Springer-Verlag, 404438.

Halliwell, G. R., Jr., and P. Cornillon, 1989: Large-scale SST anomalies associated with subtropical fronts in the western North Atlantic during FASINEX. J. Mar. Res., 47, 757-775.

$\longrightarrow$, and —-, 1990: Large-scale SST variability in the western North Atlantic subtropical convergence zone during FASINEX. Part II: Upper ocean heat balance and frontogenesis. J. Phys. Oceanogr., 20, 223-234.

- - and D. A. Byrne, 1991 a: Westward-propagating SST anomaly features in the Sargasso Sea, 1982-88. J. Phys. Oceanogr., 21, 635-649.

- -, K. H. Brink, R. T. Pollard, D. L. Evans, L. A. Regier, J. M. Toole and R. W. Schmitt, 1991 b: Descriptive oceanography during FASINEX: Medium to large-scale variability. J. Geophys. Res., (submitted).

Harrison, D. E., and R. H. Heinmiller, 1983: Upper ocean thermal variability in the Sargasso Sea July 1977-July 1978: The POLYMODE XBT program. J. Phys. Oceanogr., 13, 859-872.

Hasselmann, K., 1976: Stochastic climate models. Part I: Theory. Tellus, 28, 473-485.

Jacobs, G. A., W. Emery and G. H. Born, 1990: Least-squares fitting of barotropic and first-mode baroclinic Rossby waves to Geosat data over the Pacific Ocean. Eos, 71(43), p. 1374.

Jourdan, D., C. Boissier, A. Braun and J. F. Minster, 1990: Influence 
of wet tropospheric correction on mesoscale dynamic topography as derived from satellite altimetry. $J$. Geophys. Res., 95, 17 99318004.

Kang, Y. Q., and L. Magaard, 1982: Annual temperature fluctuations at the subtropical and subarctic fronts in the central North $\mathrm{Pa}$ cific. J. Geophys. Res., 87, 5663-5666.

Kessler, W. S., 1990: Observations of long Rossby waves in the northern tropical Pacific. J. Geophys. Res., 95, 5183-5218.

Killworth, P., 1979: On the propagation of stable baroclinic Rossby waves through mean shear flow. Deep-Sea Res., 26A, 997-1031.

Le Traon, P. Y., M. C. Rouquet and C. Boissier, 1990: Spatial scales of mesoscale variability in the North Atlantic as deduced from Geosat data. J. Geophys. Res., 95, 20 267-20 286.

McClain, E. P., W. G. Pichel and C. C. Walton, 1985: Comparative performance of AVHRR-based multichannel sea surface temperatures. J. Geophys. Res., 90, 11 587-11 601.

McWilliams, J. C., 1976: Maps from the Midocean Dynamics Experiment. Part I: Geostrophic streamfunction. J. Phys. Oceanogr., 6, 810-827.

- and W. B. Owens, 1976: Estimation of spatial covariances from the Midocean Dynamics Experiment. Tech. Note 115, National Center for Atmospheric Research, Boulder, CO, 25 pp.

MODE Group, 1978: The Midocean Dynamics Experiment. DeepSea Res., 25, 859-910.

Olson, D. B., F. A. Schott, R. J. Zantopp and K. D. Leaman, 1984: The mean circulation east of the Bahamas as determined by a recent measurement program and historical XBT data. J. Phys. Oceanogr., 14, 1470-1487.

Pratt, R. W., 1976: The interpretation of space-time spectral qualities. J. Atmos. Sci., 33, 1060-1066.

Reid, J. L., 1978: On the middepth circulation and salinity field in the North Atlantic Ocean. J. Geophys. Res., 83, 5063-5067.

Reynolds, R. W., 1979: A stochastic forcing model of sea surface temperature anomalies in the North Pacific and North Atlantic. Rep. 8, Climate Research Institute, Oregon State University, Corvallis.

Rhines, P. B., 1975: Waves and turbulence on a $\beta$ plane. J. Fluid Mech., 69(3), 417-443.

Richardson, P. L., 1983: Eddy kinetic energy in the North Atlantic from surface drifters. $J$. Geophys. Res., 88, 4355-4367.

Richman, J. G., C. Wunsch and N. G. Hogg, 1977: Space and time scales of mesoscale motion in the sea. Rev. Geophys. Space Phys., $15,385-420$.
Ro, Y. J., and P. Cornillon, 1990: Processing of Geosat data by the EOF technique.

Rossby, H. T., S. C. Riser and A. J. Mariano, 1983: The western North Atlantic-a Lagrangian viewpoint. Eddies in Marine Science, A. R. Robinson, Ed., Springer-Verlag, 66-91.

Schluessel, P., W. J. Emery, H. Grassl, and T. Mammen, 1990: On the bulk-skin temperature difference and its impact on satellite remote sensing of sea surface temperature. J. Geophys. Res., 95 , 13 341-13 356.

Schmitz, W. J., Jr., 1978: Observations of the vertical distribution of low-frequency kinetic energy in the western North Atlantic. J. Mar. Res., 36, 295-310.

_- 1989: The MODE site revisited. J. Mar. Res., 47, 131-151.

Shapiro, R., 1970: Smoothing, filtering, and boundary effects. Rev. Geophys. Space Phys., 8, 359-387.

Shen, C. Y., J. C. McWilliams, B. A. Taft, C. C. Ebbesmeyer and E. J. Lindstrom, 1986: The mesoscale spatial structure and evolution of dynamical and scalar properties observed in the northwestern Atlantic Ocean during the POLYMODE Local Dynamics Experiment. J. Phys. Oceanogr., 16, 454-482.

Stevenson, J. W., 1983: The seasonal variation of the surface mixed layer response to the vertical motion of linear Rossby waves. $J$. Phys. Oceanogr., 13, 1255-1268.

Stommel, H., P. Niiler and D. Anati, 1978: Dynamic topography and recirculation in the North Atlantic. J. Mar. Res., 36, 449468 .

Taft, B. A., E. J. Lindstrom, C. C. Ebbesmeyer, C. Y. Shen and J. C. McWilliams, 1986: Water mass structure during the POLYMODE Local Dynamics Experiment. J. Phys. Oceanogr., 16, $403-426$

Uda, M., and K. Hasunuma, 1969: The eastward subtropical countercurrent in the western North Pacific Ocean. J. Oceanogr. Soc. Japan, 25, 201-210.

Voorhis, A. D., E. H. Schroeder and A. Leetmaa, 1976: The influence of deep mesoscale eddies on surface temperature in the North Atlantic subtropical convergence. J. Phys. Oceanogr., 6, 953961.

Weller, R. A., 1991: FASINEX, a study of air-sea interaction in a region of strong oceanic gradients. J. Geophys. Res., (submitted.)

Willebrand, J., 1978: Temporal and spatial scales of the wind field over the North Pacific and North Atlantic. J. Phys. Oceanogr., 8, 1080-1094

Williams, E. J., and D. B. Olson, 1982: Mean circulation in the North Atlantic from historical XBT data. Eos, 63(3), p. 108 